\title{
Atrial Fibrillation After Cardiac Surgery - A Systematic Review and Meta-Analysis
}

\author{
Dissertation \\ zu Erlangung des akademischen Grades \\ doctor medicinae (Dr. med.) \\ vorge le gt de m Rat der Me dizinischen Fakultät \\ der Frie drich-Schiller-Universität Jena
}

von Túlio Magno de Melo Caldonazo

geboren am 13.08.1995 in Varginha, Brasilien 


\section{Gutachte r}

1. Prof. Dr. Torsten Doenst - Klinik für Herz- und Thoraxchirurgie - Universitätsklinikum Jena

2. Prof. Dr. Ralf Surber - Klinik für Innere Medizin I - Universitätsklinikum Jena

3. Prof. Dr. Christian Hagl - Herzchirurgische Klinik - Ludwig-Maximilians-Univers ität München

Tag der öffentlichen Verteidigung: 17.08.2021 


\section{Abbre viations}

AF: atrial fibrillation

CABG: coronary artery bypass grafting

COPD: chronic obstructive pulmonary disease

ECG: electrocardiogram

ICU: intensive care unit

IRR: incidence rate radio

NSR: normal sinus rhythm

OR: odds ratio

POAF: new-onset post-operative atrial fibrillation

SMD: standardized mean difference 


\section{$\underline{\text { Table of Contents }}$}

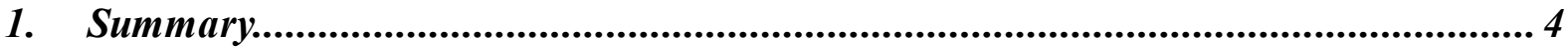

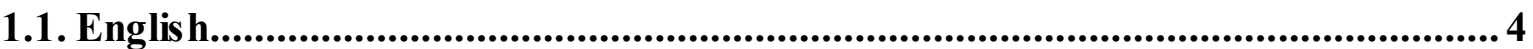

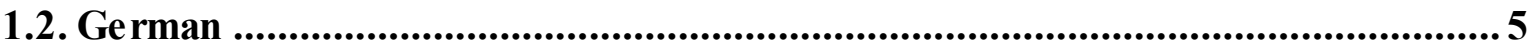

2. Introduction ........................................................................................................ 7

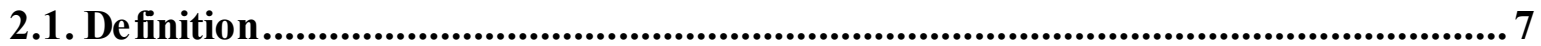

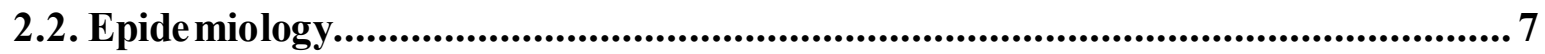

2.3. Pathophysiology ..................................................................................................7

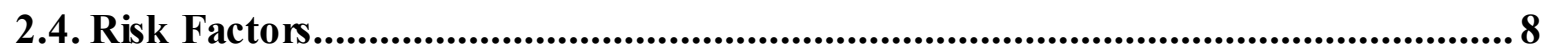

2.5. Possible Dele te rious Effect .................................................................................9

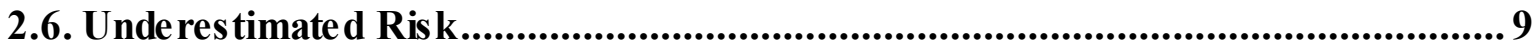

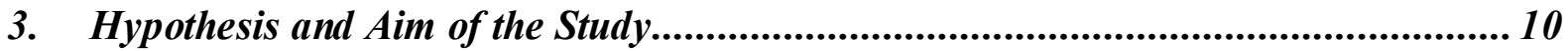

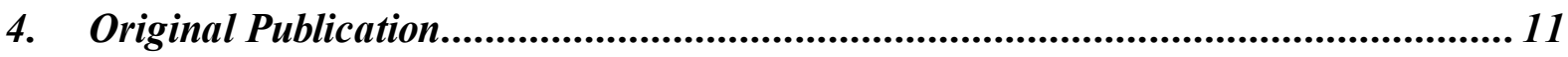

4.1. Manus cript ........................................................................................................... 11

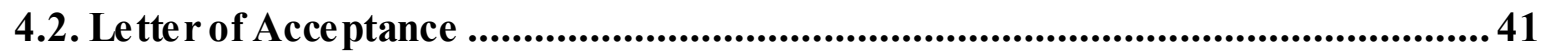

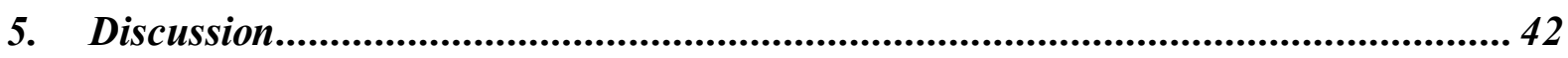

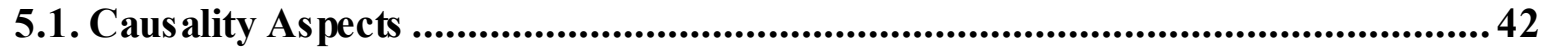

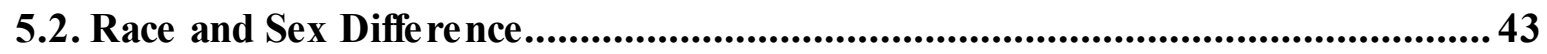

5.3. Long-standing Atrial Fibrillation as a Consequence of POAF ........................... 44

5.4. Management and Possible Tre atments ................................................................ 44

5.5. Curre nt Prospective Trials on POAF........................................................... 46

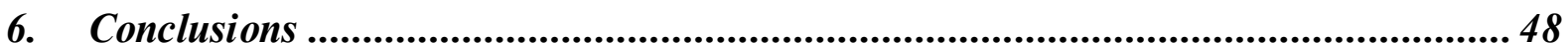

7. Bibliography References..................................................................................... 49

8. Appendix............................................................................................................. 58

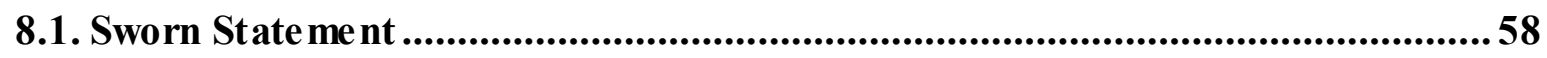

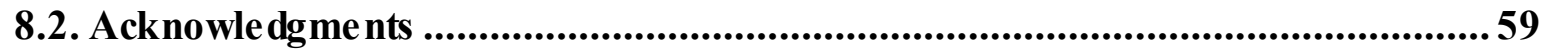




\section{Summary}

\subsection{Englis h}

\section{Background}

New-onset post-operative atrial fibrillation (POAF) after cardiac surgery is common, with rates up to $60 \%$. POAF has been associated with early and late stroke, but its association with other cardiovascular outcomes is less known. The objective of this study was to perform a systematic review and a meta-analysis of the studies reporting the association of POAF with peri-operative and long-term outcomes in cardiac surgery.

\section{Methods}

We performed a systematic review and a meta-analysis of studies presenting outcomes for cardiac surgery based on the presence or absence of POAF. Three libraries were assessed (MEDLINE, EMBASE and Cochrane Library) and 57 studies (total of 246,340 patients) were selected. Peri-operative mortality was the primary outcome. Inverse variance method and random model were performed. Leave-one-out analysis, sub-group analyses and metaregression were conducted.

\section{Results}

POAF was associated with peri-operative mortality (odds ratio $[\mathrm{OR}]=1.92,95 \%$ confidence interval $[\mathrm{CI}] 1.58 ; 2.33)$, peri-operative stroke $(\mathrm{OR}=2.17,95 \% \mathrm{CI} 1.90 ; 2.49)$, peri-operative myocardial infarction $(\mathrm{OR}=1.28,95 \% \mathrm{CI} 1.06 ; 1.54)$, peri-operative acute renal failure $(\mathrm{OR}=$ 2.74, 95\% CI 2.42; 3.11), hospital length of stay (standardized mean difference $[\mathrm{SMD}]=0.80$, $95 \%$ CI 0.53 ; 1.07), ICU stay ( $\mathrm{SMD}=0.55,95 \%$ CI 0.24; 0.86), long-term mortality (incidence rate ratio $[I R R]=1.54,95 \%$ CI 1.40; 1.69), long-term stroke $(\operatorname{IRR}=1.33,95 \%$ CI 1,21;1,46) and long-standing persistent atrial fibrillation ( $\mathrm{IRR}=4.73,95 \% \mathrm{CI} 3.36 ; 6.66)$.

\section{Conclusion}

The results suggest that POAF in cardiac surgery is associated with an increased occurrence of most short and long-term cardiovascular adverse events. However, the direct causality of this association remains to be established. 


\subsection{Ge rman}

\section{Hinte rgrund und Zie le de r Studie}

Neu auftretendes postoperatives Vorhofflimmern (POAF) nach einer Herzoperation ist mit Raten von bis zu 60\% häufig. POAF wurde bereits mit frühem und spätem Schlaganfall in Verbindung gebracht, ob aber ein Zusammenhang mit anderen kardiovaskulären Ereignissen besteht ist noch weitgehend unbekannt. Das Ziel dieser Studie war die Erstellung einer systematischen Datenübersicht, sowie die Durchführung einer Metaanalyse anhand von Studien, die den Zusammenhang von POAF mit perioperativen und langfristigen Ergebnissen in der Herzchirurgie untersucht haben.

\section{Methodik}

Wir erstellten eine systematische Datenübersicht und führten eine Metaanalyse anhand von Studien durch, die Ergebnisse in der Herzchirurgie abhängig vom Vorhandensein oder Fehlen von POAF präsentierten. Die MEDLINE, EMBASE und Cochrane Library wurden durchsucht und 57 Studien (insgesamt 246.340 Patienten) ausgewählt. Der primäre Endpunkt war die perioperative Mortalität. Inverse Varianz und Random Modell Methoden wurden angewendet. Zudem wurden eine Leave-one-out Analyse, Untergruppenanalysen und eine Meta-Regression durchgeführt.

\section{Ergebnis se}

POAF war mit perioperativer Sterblichkeit (Odds Ratio $[\mathrm{OR}]=1,92,95 \%$ Konfidenzinterva 11 [CI] 1,58; 2,33), perioperativem Schlaganfall $(\mathrm{OR}=2,17,95 \%$ CI 1,90; 2,49), perioperativem Myokardinfarkt $(\mathrm{OR}=1,28,95 \% \mathrm{CI} 1,06 ; 1,54)$, perioperativem akuten Nierenversagen (OR $=2,74,95 \%$ CI 2,42; 3,11), der Aufenthaltsdauer im Krankenhaus (standardisierte mittlere Differenz $[\mathrm{SMD}]=0,80,95 \%$ CI 0,53; 1,07) und auf der Intensivstation $(\mathrm{SMD}=0,55,95 \% \mathrm{CI}$ 0,24; 0,86), Langzeitsterblichkeit (Inzidenzratenverhältnis [IRR] = 1,54, 95\% CI 1,40; 1,69), langfristig auftretendem Schlaganfall (IRR = 1,33) 95\% CI 1,21; 1,46) und lang anhaltendem Vorhofflimmern $(\mathrm{IRR}=4,73,95 \%$ CI 3,36; 6,66) assoziiert. 


\section{Schlus s folge rungen}

Die Ergebnisse legen nahe, dass POAF in der Herzchirurgie mit einem erhöhten Auftreten einer ganzen Reihe von kurz- und langfristigen kardiovaskulären unerwünschten Ereignissen verbunden ist. Ein Kausalzusammenhang kann jedoch mit dieser Analyse nicht erstellt werden. 


\section{Introduction}

\subsection{De finition}

New-onset postoperative atrial fibrillation (POAF) is defined as the new development of atrial fibrillation after surgery in patients with previous sinus rhythm (NSR) and no history of atrial fibrillation (AF) (Lubitz et al. 2015). It is the most important type of secondary AF (AF resulting from identifiable, primary, acute conditions) (Lubitz et al. 2015).

The POAF episodes are often brief, paroxysmal and asymptomatic (Funk et al. 2003), with a peak incidence between days 2 and 4 after surgery (Funk et al. 2003, Mathew et al. 2004). Recurrences are frequent, especially during the first postoperative week (Lee et al. 2000).

\subsection{Epide miology}

POAF is a common complication of surgery, with an incidence varying from $10-63 \%$ (Villareal et al. 2004, Echahidi et al. 2008) for cardiac surgeries (38-63\% for valve surgery and $10-33 \%$ for coronary artery bypass graft surgery) (Turagam et al. 2016) and from $0.3-30 \%$ for non-cardiac surgeries (Christians et al. 2001, Echahidi et al. 2008).

The incidence of POAF has increased continuously over the past decades, and the reason is probably related with the aging process of the population undergoing heart surgery.

Nowadays, POAF represents approximately one-third of cases of secondary atrial fibrillation (Greenberg et al. 2017), and AF recurrence rate in patients who develop POAF after cardiothoracic surgery $(46 \%)$ is lower than that in patients with POAF after non-thoracic surgery (64\%) (Lubitz et al. 2015), supporting a greater role of transient factors than of a preexisting substrate.

\subsection{Pathophysiology}

Underlying mechanisms are not completely defined but they include intraoperative and postoperative phenomena combined with the presence of pre-existing factors. This combination results in a totally vulnerable scenario for atrial fibrillation induction and maintenance (Nattel 2002, Andrade et al. 2014, Heïman et al. 2018, Dobrev et al. 2019). 
Dobrev and colleagues (Dobrev et al. 2019) described in a structured model that POAF is mainly promoted by factors inducing atrial arrhythmogenic remodeling before surgery, as well as factors increasing the substrate vulnerability or the type/number of triggers postoperatively. Activation of the autonomic nervous system (Hogue et al. 1998, Echahidi et al. 2008) and local inflammation - related to surgical lesions (Gaudino et al. 2003, Ishii et al. 2005, Echahidi et al. 2008) and postoperative pericarditis (Ishii et al. 2005) - are the principal transient factors associated.

The literature showed that drugs that increase sympathetic tone increase the incidence of POAF (Feneck et al. 2001, Argalious et al. 2005) and perioperative $\beta$-blocker use reduces the incidence of POAF (White et al. 1984, Lamb et al. 1988). The incidence of POAF is lower after cardiac transplantation than after other forms of cardiac surgery (Argalious et al. 2005) and pharmacological denervation with botulinum toxin prevents POAF (Pokushalov et al. 2015). Factors that reinforce the idea from a combined sympathovagal triggering of POAF (Amar et al. 2003).

In addition, elevated preoperative plasma levels of IL-2 and IL-6 (important cytokines that mediate inflammatory responses) are also reported in some studies (Gaudino et al. 2003, Ucar et al. 2007, Pretorius et al. 2007, Haket al. 2009). Postoperative activation of C-reactive protein has been also associated with POAF occurrence (Kaireviciute et al. 2010), and corticosteroids can reduce the incidence of POAF by inhibiting cytokine release (Ho und Tan 2009).

In summary, POAF appears to be promoted by addition of transient postoperative factors on a pre-existing and surgery-induced substrate, resulting in a re-entry structural and electrical remodeling.

\subsection{Risk Factors}

Atrial remodeling is an important predisposing factor for POAF, therefore elements that interfere in this situation play a significant role in this pathology. Registries have been showed the independent association between some specific factors and POAF in cardiac surgery, such as: elevated age, male sex, congestive heart failure, arterial hypertension, obesity, white ethnicity, chronic obstructive pulmonary disease (COPD), mitral valve surgery, use of intraaortic balloon pump, long cross-clamp time and bicaval cannulation (Aranki et al. 1996, 
Mathew et al. 1996, Almassi et al. 1997, Zaman et al. 2000, Funk et al. 2003, Mathew et al. 2004, Auer et al. 2004, Zacharias et al. 2005, Banach et al. 2006, Shen et al. 2011, Dobrev et al. 2019).

\subsection{Pos sible Deleterious Effect}

POAF as a post-operative complication has major adverse consequences for patients and the health care system, including increased risks of post-operative stroke, peri-operative acute kidney injury (El-Chami et al. 2010, Thorén et al. 2020), increased length of hospital stay (Echahidi et al. 2008, Almassi et al. 2019) and mortality (El-Chami et al. 2010, Thorén et al. 2020). Notably is also the fact that the high AF recurrence rates in patients with POAF make this condition a clear marker of subsequent risk of long-standing persistent AF.

\subsection{Underestimated Ris $k$}

Despite the high incidence, POAF has generally not been considered harmful, because of its perceived reversibility. Evidence from prospective randomized trial suggests that the vast majority of patients after CABG surgery return to normal sinus rhythm within 60 days, irrespective of the therapeutic strategy (rhythm control or rate control) (Gillinov et al. 2016).

At the same time, several studies demonstrate the hazardous potential of POAF in several clinical endpoints such as mortality, stroke, heart failure and chronic AF (Almassi et al. 2019, Thorén et al. 2020, Filardo et al. 2020).

Thus, it appears unclear whether POAF is harmless or harmful and the current perception of POAF may be influenced by individual publications. 


\section{Hypothes is and Aim of the Study}

Based on the perceived controversy from the recent randomized trial evidence (Gillinov et al. 2016) and the associations presented from propensity matched studies (Schwann et al. 2018, Filardo et al. 2020), we set out to systematically review the entire literature and thoroughly address the impact of POAF on clinical outcomes, focusing on all classic cardiovascular adverse events during the peri-operative period and long-term follow-up. 


\section{Original Publication}

\subsection{Manus cript}

Atrial Fibrillation after Cardiac Surgery -

A Systematic Review and Meta-Analysis

Tulio Caldonazo, $\mathrm{MD}^{\mathrm{a}^{*}}$, Hristo Kirov, $\mathrm{MD}^{\mathrm{a}^{*}}$, Mohamed Rahouma, MD ${ }^{\mathrm{b}}$, N. Bryce Robinson $\mathrm{MD}^{\mathrm{b}}$, Michelle Demetres, MLIS ${ }^{\mathrm{c}}$, Mario Gaudino, MD MSCE ${ }^{\mathrm{b}}$, Torsten Doenst, MD PhDa and POAF-MA Group.

aDepartment of Cardiothoracic Surgery, Friedrich-Schiller-University Jena, Germany. ${ }^{b}$ Department of Cardiothoracic Surgery at New York Presbyterian, Weill Cornell Medical Center, USA.

'Samuel J. Wood Library and C.V. Starr Biomedical Information Center, Weill Cornell Medicine, New York, NY, USA.

*Both authors contributed equally to this work.

Funding: The author's research was supported by the National Institutes of Health $-\mathrm{Be}-$ thesda, US (R01-HL131517, R01-HL136389, and R01-HL089598 to DD) and the German Research Foundation - Bonn, Germany (Do769/4-1 to DD and Do602/9-1 to TD).

Conflict of interest: None.

\section{Address for Correspondence:}

Torsten Doenst, M.D.

Department of Cardiothoracic Surgery

University of Jena

101 Erlanger Allee

07747 Jena, Germany

Tel.: 0049.3641.9322.901

Fax: 0049.3641.9322.902 Abstract word count: 242

E-mail: doenst@med.uni-jena.de $\quad$ Total word count: 2592

\section{POAF-MA Group:}

1. Dobromir Dobrev, MD (Department of Medicine and Research Center, Montreal Heart Institute and Université de Montréal, Canada; and Institute of Pharmacology, West German Heart and Vascular Center, University Duisburg-Essen, Germany);

2. Michael A. Borger, MD PhD (Department of Cardiac Surgery, Leipzig Heart Center, Germany);

3. Michael Kiehntopf, MD (Institute of Clinical Chemistry and Laboratory Diagnostics, FriedrichSchiller-University Jena, Germany);

4. Katherine Skoloff, BA (Department of Cardiothoracic Surgery at New York Presbyterian, Weill Cornell Medical Center, USA) 


\section{GLOSSARY OF ABBREVIATIONS}

52 AF: atrial fibrillation

53 CABG: coronary artery bypass grafting

54 ECG: electrocardiogram

55 IRR: incidence rate radio

56 NSR: normal sinus rhythm

57 OR: odds ratio

58 POAF: new-onset post-operative atrial fibrillation

59 SMD: standardized mean difference 
60 Central Message: POAF is associated with peri-operative mortality, stroke, myocardial 61 infarction, acute renal failure and long-term mortality, stroke, long-standing persistent AF, 62 hospital and ICU length of stay. 
63 Perspective Statement: While a directly causal relationship between POAF and these adverse 64 cardiovascular events cannot be totally established, the information represents an important 65 milestone for future hypotheses about its etiology and for designing randomized trials 66 addressing its prevention/treatment. 


\section{ABSTRACT}

Objective: New-onset post-operative atrial fibrillation (POAF) after cardiac surgery is common, with rates up to $60 \%$. POAF has been associated with early and late stroke, but its association with other cardiovascular outcomes is less known. The objective was to perform a meta-analysis of the studies reporting the association of POAF with perioperative and long-term outcomes in cardiac surgery.

Methods: We performed a systematic review and a meta-analysis of studies presenting outcomes for cardiac surgery based on the presence or absence of POAF. MEDLINE, EMBASE and Cochrane Library were assessed, 57 studies (246,340 patients) were selected. Peri-operative mortality was the primary outcome. Inverse variance method and random model were performed. Leave-one-out analysis, sub-group analyses and meta-regression were conducted.

Results: POAF was associated with peri-operative mortality (odds ratio $[\mathrm{OR}]=1.92$, $95 \%$ confidence interval [CI] $1.58 ; 2.33)$, peri-operative stroke $(\mathrm{OR}=2.17,95 \% \mathrm{CI} 1.90$; $2.49)$, peri-operative myocardial infarction $(\mathrm{OR}=1.28,95 \% \mathrm{CI} 1.06 ; 1.54)$, perioperative acute renal failure $(\mathrm{OR}=2.74,95 \%$ CI $2.42 ; 3.11)$, hospital (standardized mean difference $[\mathrm{SMD}]=0.80,95 \% \mathrm{CI} 0.53 ; 1.07)$ and ICU stay $(\mathrm{SMD}=0.55,95 \% \mathrm{CI}$ $0.24 ; 0.86$ ), long-term mortality (incidence rate ratio $[\mathrm{IRR}]=1.54,95 \%$ CI $1.40 ; 1.69$ ), long-term stroke $(\mathrm{IRR}=1.33,95 \%$ CI 1,$21 ; 1,46)$ and long-standing persistent atrial fibrillation (IRR $=4.73,95 \%$ CI $3.36 ; 6.66)$.

Conclusion: The results suggest that POAF in cardiac surgery is associated with an increased occurrence of most short and long-term cardiovascular adverse events. However, the causality of this association remains to be established.

\section{KEYWORDS}

post-operative atrial fibrillation, atrial fibrillation, heart surgery, arrhythmia 


\section{INTRODUCTION}

New-onset postoperative atrial fibrillation (POAF) is defined as the new development of atrial fibrillation after surgery in patients with previous sinus rhythm (NSR) and no history of atrial fibrillation $(\mathrm{AF})^{1}$. It is the most important type of secondary $\mathrm{AF}$ ( $\mathrm{AF}$ resulting from identifiable, primary, acute conditions $)^{1}$.

POAF is a common complication of surgery, with an incidence varying from $10-63 \%$ for cardiac surgeries (38-63\% for valve and $10-33 \%$ for coronary artery bypass graft surgery) ${ }^{2}$. Despite the high incidence, POAF has generally not been considered harmful, because of its perceived reversibility. Evidence from prospective randomized trials suggests that the vast majority of patients after CABG surgery return to normal sinus rhythm within 60 days $^{3}$.

In contrast, other non-randomized evidence suggests that POAF may be associated with increased risks of post-operative stroke, peri-operative acute kidney injury ${ }^{4,5}$, increased length of hospital stay ${ }^{6,7}$ and mortality ${ }^{4,5}$. Even meta-analyses have addressed this topic, but limited their assessment to stroke and peri-operative mortality ${ }^{8-11}$, mixed cardiac and non-cardiac surgery patients ${ }^{10}$ or are already outdated because many important studies appeared only recently ${ }^{8-12}$.

Based on the perceived controversy from the recent randomized trial evidence ${ }^{3}$ and the associations presented from propensity matched studies ${ }^{13,14}$ and meta-analyses ${ }^{8-11}$, we set out to systematically review the entire literature and thoroughly address the impact of POAF on clinical outcome, focusing on all classic cardiovascular adverse events during the perioperative period and long-term follow-up.

\section{METHODS}

7 This analysis was prospectively registered on the International Prospective Register of Systematic Reviews in Health and Social Care (PROSPERO, ID number CRD42020181049). 
119 Ethical and IRB approval was not required for this analysis as no human or animal subjects

120 were involved.

\section{Search strategy}

122 A medical librarian (MD) performed a comprehensive literature search to identify contemporary studies comparing outcomes in patients with POAF with those in NSR after cardiac surgery. Searches were run on April 22, 2020 in the following databases: Ovid MEDLINE® (ALL; 2008 to present); Ovid EMBASE (1974 to present); and The Cochrane Library (Wiley). The full search strategy for Ovid MEDLINE is available in Supplementary Table 1.

\section{Study selection and eligibility criteria}

The study selection was guided by Preferred Reporting Items for Systematic Reviews and Meta-Analyses (PRISMA) strategy. After de-duplication, records were screened by two independent reviewers (TC and $\mathrm{HK}$ ). Any discrepancies and disagreements were resolved by a third author (TD). All titles and abstracts were reviewed against pre-defined inclusion and exclusion criteria. Studies were considered for inclusion if they were written in English and reported direct comparison between POAF patients and NSR patients following cardiac surgery and had at least 1 outcome of interest reported. Studies evaluating non-cardiac surgeries, conference abstracts and proceedings and case reports were excluded. Included studies indicated clearly that the patients were evaluated on admission and that they had also no previous history of alleged atrial fibrillation.

Following the first round of screening, full text was pulled for selected studies for a second round of eligibility screening. Reference lists for articles in these selected studies were also searched for any relevant articles not captured by the original search strategy.

\section{Data abstraction and quality assessment}


143 The data extraction and the quality assessment were performed independently by two different

144 investigators (TC and HK) and verified by a third investigator (TD) for accuracy. The following

145 variables were extracted: age, sex, left ventricular ejection fraction, hypertension, diabetes,

146 chronic obstructive pulmonary disease, prior cerebrovascular accident, prior myocardial

147 infarction, prior use of beta-blockers, previous heart surgery, chronic renal failure, serum

148 creatinine level.

149 For short term binary outcomes, number of events were extracted from the included studies and

150 expressed as odds ratio, for long term outcomes, incidence rate ratio was estimated.

151 Risk of bias was assessed based on Newcastle-Ottawa assessment scale (Supplementary

152 Table 2) ${ }^{15}$. Publication bias was also assessed for the primary outcome (Supplementary

153 Figure 1).

\section{Outcomes and effect summary}

155 The primary outcome was peri-operative mortality.

156 Secondary outcomes were long-term mortality, peri-operative and long-term stroke, peri-

157 operative myocardial infarction, acute renal failure, long-standing persistent AF, hospital

158 length of stay and intensive care unit length of stay. The peri-operative outcomes were defined

159 as in-hospital or 30-day events.

160 Subgroup analysis of recent studies (published year: up to 2010 and after 2010), a sub-group

161 analysis based on the method used for rhythm monitoring (comparison between continuous

162 monitoring in intensive care unit and irregular electrocardiography until discharge vs.

163 continuous monitoring during entire hospital stay) and a subgroup analysis addressing the type

164 of surgery (CABG, CABG and valve surgery or valve surgery) were performed to test the

165 solidity of the main analysis.

166 Data analysis

167 Peri-operative binary outcomes were reported as odds ratios (OR) while long-term outcomes, 
were reported as incidence rate ratio (IRR); for both estimates the generic inverse variance method was used and 95\% confidence intervals (CIs) were also presented. Sub-group analyses of the primary outcome were reported as OR associated with subgroup difference P-interaction (SGD-P) with 95\% CI. Continuous outcomes were expressed as standardized mean difference (SMD) with 95\% CI.

Random effect meta-analysis was performed using "metafor" and "meta" package ${ }^{16,17}$. NSR was the reference for all pairwise comparisons. Heterogeneity was reported as low (I2 $=0 \%^{-}$ $25 \%$ ), moderate $(\mathrm{I} 2=26 \%-50 \%)$, or high $(\mathrm{I} 2>50 \%)^{18}$. Leave-one-out analysis for the primary outcome was performed to assess the robustness of the obtained estimate. Meta-regression was used to explore the effects of age, sex, left ventricle ejection fraction, comorbidities, use of beta-blockers and previous heart surgery on the OR of the primary outcome.

Statistical significance was set at the 2-tailed 0.05 level, without multiplicity adjustments. All statistical analyses were performed using R (version 3.3.3, R Project for Statistical Computing) within RStudio.

\section{RESULTS}

\section{Description of included studies}

A total of 6,632 records were identified through database searching. After duplicate records were removed, a total of 4,541 citations were retrieved and their titles and abstracts were screened. A total of 57 studies were included in the final analysis, with a total of 246,340 patients. The full Preferred Reporting Items for Systematic Reviews and Meta-Analyses (PRISMA) flow diagram outlining the study selection process is available in Figure $\mathbf{1}^{19,20}$. A complete list of studies included in the final analysis is presented in Supplementary Table 3. 
191 All studies were observational. Sixteen studies were multicenter; 22 originated from the United

192 States, 3 from Canada, 3 from Netherlands, 3 from Sweden, 3 from Brazil, 2 from Finland, 2

193 from Turkey, 2 from Iran, 2 from Australia, 2 from Korea, 2 from the United Kingdom, 1 each

194 from Denmark, Serbia, Austria, Japan, Taiwan, Israel, Saudi Arabia, Malaysia, and Colombia.

195 The number of patients in each study ranged from 44 to 49,264 . The mean age ranged from

19654.6 to 77.4 years. The percentage of female sex in each study ranged from 0.9 to $68.0 \%$. In

197 terms of patient comorbidities, the prevalence of hypertension ranged from 30.4 to $97.0 \%$, the

198 prevalence of diabetes ranged from 3.4 to $66.7 \%$, the prevalence of chronic obstructive

199 pulmonary disease ranged from 0.5 to $41.8 \%$, the prevalence of prior cerebrovascular accident

200 ranged from 0.6 to $29.2 \%$, the prevalence of prior myocardial infarction ranged from 2,2 to

$20173,0 \%$ and the prevalence of chronic renal failure ranged from 1.0 to $15.0 \%$ (Supplementary

202 Table 4).

203 Outcomes

204 Detailed results of the meta-analysis are outlined in Figure 6 - Graphical Abstract and 205 summarized in Table 1.

\section{Primary outcome}

207 Occurrence of POAF was associated with increased peri-operative mortality $(\mathrm{OR}=1.92,95 \%$

208 CI 1.58; 2.33, $\mathrm{p}<0.0001$, Figure 2).

209 This finding was consistent in sub-analyses of studies published before and after $2010(\mathrm{OR}=$

$2102.06,95 \%$ CI $1.32 ; 3.20$, and $\mathrm{OR}=1.87,95 \%$ CI $1.51 ; 2.32$, p-interaction $=0,71$, Figure 3$)$, in

211 studies that used continuous monitoring in intensive care unit and daily electrocardiography

212 until discharge and continuous monitoring during entire hospital stay $(\mathrm{OR}=1.95,95 \% \mathrm{CI} 1.49$;

2132.56 , and $\mathrm{OR}=3.25,95 \%$ CI $1.31 ; 8.07$, p-interaction=0,30, Figure 4) and in individual studies

214 addressing just $\mathrm{CABG}, \mathrm{CABG}$ and valve surgery and, finally, just valve surgery $(\mathrm{OR}=2.40$,

$21595 \%$ CI $1.86 ; 3.09, \mathrm{OR}=1.66,95 \%$ CI $0.75 ; 3.68$, and $\mathrm{OR}=0.89,95 \%$ CI $0.28 ; 2.81, \mathrm{p}-$ 
216 interaction $=0,19$, Figure 5). Leave-one-out analysis confirmed the solidity of the pooled

217 estimate (Supplementary Figure 2).

\section{Secondary outcomes}

POAF was associated with peri-operative stroke $(\mathrm{OR}=2.17,95 \%$ CI $1.90 ; 2.49, \mathrm{p}<0.0001$, Supplementary Figure 3), peri-operative myocardial infarction $(\mathrm{OR}=1.28,95 \%$ CI 1.06; 1.54 , $\mathrm{p}=0.0094$, Supplementary Figure 4$)$ and peri-operative acute renal failure $(\mathrm{OR}=2.74,95 \% \mathrm{CI}$ 2.42; 3.11, $<<0.0001$, Supplementary Figure 5).

POAF was also associated with hospital length of stay $(\mathrm{SMD}=0.80,95 \%$ CI $0.53 ; 1.07$, $\mathrm{p}<0.0001$, Supplementary Figure 6 ) and stay in the intensive care unit $(\mathrm{SMD}=0.55,95 \% \mathrm{CI}$ 0.24; 0.86, $<<0.0001$, Supplementary Figure 7).

Finally, POAF was associated with long-term mortality $(\mathrm{IRR}=1.54,95 \% \mathrm{CI} 1.40 ; 1.69$, $\mathrm{p}<0.0001$, Supplementary Figure 8), long-term stroke $(\mathrm{IRR}=1.33,95 \%$ CI $1.21 ; 1.46$, $p<0.0001$, Supplementary Figure 9) and long-standing persistent AF (IRR $=4.73,95 \%$ CI 3.36; 6.66, $\mathrm{p}<0.0001$, Supplementary Figure 10).

\section{Meta-regression}

At meta-regression, the proportion of female patients was inversely associated with the OR for the primary outcome (beta $=-0.0293, \mathrm{p}=0.0043$ ). The proportion of diabetes and presence of prior myocardial infarction were associated with "higher" OR for the primary outcome (beta= 0.0144, $\mathrm{p}=0.0056$ and $0.0122, \mathrm{p}=0.0303$; respectively - Supplementary Table 5).

\section{DISCUSSION}

Our analysis suggests that POAF in cardiac surgery is associated with an increased occurrence of most short and long-term cardiovascular adverse events. Specifically, POAF appears to be 
associated with peri-operative mortality, peri-operative stroke, peri-operative myocardial infarction, peri-operative acute renal failure and long-term mortality, long-term stroke, longstanding persistent AF, as well as hospital length of stay and intensive care unit length of stay (Video 1).

However, our results cannot prove causation and it is unclear if POAF was involved in the pathogenesis of the associated outcomes, or if it was only a marker of increased cardiovascular risk. Recent data suggest that a pre-existing arrhythmogenic substrate exists before surgery and discriminates who is going to develop POAF. It may potentially explain the long-term recurrence rate of $\mathrm{AF}$ and the occurrence of other cardiovascular events ${ }^{21}$.

It is known that factors such as inflammation, myocardial ischemia and autonomic nervous system activation are thought to be superimposed on susceptible atrial substrates, making the atrium vulnerable to $\mathrm{AF}$ induction and maintenance ${ }^{22}$. In addition, pre-existing atrial fibrosis may predispose patients to developing atrial fibrillation, which may have implications for the timing of cardiac interventions ${ }^{23}$.

Different clinical factors have also been described that may contribute to the development of POAF. They range from pre-operative (hypertension, myocardial ischemia, valvular abnormalities), through peri-operative (surgical trauma, local inflammation, large fluid shifts, electrolyte disturbances) to post-operative conditions and events (inotropic drugs, atrial pacing, pneumonia) ${ }^{6,22}$. Thus, the combination of pre-disposing substrates for the natural development of AF with peri-operative events would then increase the risk of POAF. This conceptual model could explain the differences between classic surgery and TAVI for aortic valve replacement 24,25 and the significant rate of POAF in non-cardiac surgery ${ }^{26}$.

Although previous meta-analyses addressed this topic, they had significant limitations. For instance, even the latest publication in the field ${ }^{11}$ analyzed only 2 outcomes (stroke and mortality) and did not include some of the important contemporary publications on POAF post- 
cardiac surgery with more than 20,000 patients $4,7,12,13,27-30$. To the best of our knowledge, our comprehensive meta-analysis is the first to assess all important cardiovascular adverse events. We provide a broad overview of a number of important clinical outcomes and their association with POAF after cardiac surgery. Most of the analyzed publications were contemporary, with $75 \%$ of them (43 studies) published in the last 10 years. Furthermore, our sub-group analyses address some key issues when it comes to studies investigating POAF: the method used for rhythm monitoring and the type of cardiac surgical procedure. Both could potentially impact the results (i.e., the incidence of POAF can substantially vary between studies that use continuous monitoring for the entire in-hospital stay vs daily ECG after ICU discharge; and also between studies with different types of surgery procedures). We are the first to address those aspects as well as the first to compare the results of modern studies compared to the ones published before 2010. Additionally, we performed a meta-regression to measure the effect of 12 different pre-operative factors. The profound statistical evaluation of the topic provides robustness to the associations and underscores the previous publications. The outcomes of our meta-analysis are relevant as a significant number of patients after cardiac surgery develop POAF.

A recent STS-database analysis illustrates the magnitude of this problem ${ }^{31}$. According to this study in the year 2017 in the US 64,751 of 233,022 patients undergoing CABG, aortic and mitral valve surgeries (or combinations of those) developed POAF ${ }^{31}$. Considering all cardiac surgery procedures performed in the US per year, this finding would translate into approximately 100,000 patients that are affected from POAF per year only in the US. Aranki et al ${ }^{32}$ demonstrated that POAF can result in an extra cost of $\$ 10,000$ to $\$ 11,500$ to the hospital per patient developing this complication in the US. Furthermore, using the above numbers and American Heart Association (AHA) statistics assuming a POAF incidence of 30\%, the extra cost due to POAF can be calculated to exceed $\$ 2$ billion/year ${ }^{6}$. 
Considering the possible negative effects of POAF, patients and physicians may be reluctant to recommend/undergo surgery. However, it is important to note that current indications for cardiac surgery are often free of alternatives (e.g., endocarditis), and the generated outcomes are often still superior to their existing interventional (i.e., TAVI) or conservative alternatives with regards to long-term perspective $25,33,34$. It therefore appears that the positive effects of surgery outweigh the negative influence of POAF.

Given the association of POAF with worse peri-operative and long-term outcomes, the interest in this topic has recently grown. Based on the assumption that successful prevention or treatment of AF may be able to further improve outcomes of cardiac surgery, randomized trials have already been performed or recently initiated. Some of them have concentrated on preventing or reducing the incidence of $\mathrm{POAF}^{35}$ and others on the treatment and prevention of adverse events. The Anticoagulation for New-Onset Post-Operative Atrial Fibrillation after CABG (PACES) trial of the cardiothoracic surgical trials network (CTSN) [NCT04045665] is a good example of the latter.

In this context, our comprehensive meta-analysis provides a broad overview on POAF and its association with the most important clinical outcomes. Thus, the information we present might be useful when building future hypotheses or designing future randomized control trials on this topic.

\section{STUDY STRENGTH AND LIMITATIONS}

This analysis was conducted at study level rather than patient level. All studies were observational in nature. However, there are no randomized trials addressing this issue, which is not unexpected since equipoise for an adequate conservative control group does not exist. Another limitation of this study is the fact that patients with preexisting episodes of silent atrial fibrillation preoperatively might have also been included in the individual studies. However 
314 this possibility exists for both investigated groups (NSR and POAF).

315 Since one of the inclusion criteria for the review was general studies concerning POAF, the

316 aggregate study population was potentially heterogeneous. We pooled related outcomes and

317 included the definitions of others that may be different among different studies, as acute renal

318 failure and long-persistent AF (Supplementary Table 6).

319 We investigated the greatest number of contemporary studies so far and analyzed 9 different

320 outcomes. Moreover, we performed different subgroup analyses and a meta-regression of 12

321 different pre-operative factors.

322

324 POAF after cardiac surgery appears to be associated with increased occurrence of a plethora of

325 cardiovascular adverse events. However, the causality of these associations remains to be 326 established. 
327 Acknowledgements: We thank Mr. Benjamin May for editorial assistance. 


\section{BIBLIOGRAPHIC REFERENCES}

1. Lubitz SA, Yin X, Rienstra M, et al. Long-term outcomes of secondary atrial fibrillation in the community: the Framingham Heart Study. Circulation. 2015;131:1648-1655.

2. Turagam MK, Mirza M, Werner PH, et al. Circulating Biomarkers Predictive of Postoperative Atrial Fibrillation. Cardiol Rev. 2016;24:76-87.

3. Gillinov AM, Bagiella E, Moskowitz AJ, et al. Rate Control versus Rhythm Control for Atrial Fibrillation after Cardiac Surgery. N Engl J Med. 2016;374:1911-1921.

4. Thorén E, Wernroth ML, Christersson C, Grinnemo KH, Jidéus L, Ståhle E. Compared with matched controls, patients with postoperative atrial fibrillation (POAF) have increased long-term AF after $\mathrm{CABG}$, and POAF is further associated with increased ischemic stroke, heart failure and mortality even after adjustment for AF. Clin Res Cardiol. 2020.

5. El-Chami MF, Kilgo P, Thourani V, et al. New-onset atrial fibrillation predicts longterm mortality after coronary artery bypass graft. J Am Coll Cardiol. 2010;55:13701376.

6. Echahidi N, Pibarot P, O'Hara G, Mathieu P. Mechanisms, prevention, and treatment of atrial fibrillation after cardiac surgery. J Am Coll Cardiol. 2008;51:793-801.

7. Almassi GH, Hawkins RB, Bishawi M, et al. New-onset postoperative atrial fibrillation impact on 5-year clinical outcomes and costs. The Journal of Thoracic and Cardiovascular Surgery. 2019.

8. Kaw R, Hernandez AV, Masood I, Gillinov AM, Saliba W, Blackstone EH. Short- and long-term mortality associated with new-onset atrial fibrillation after coronary artery bypass grafting: a systematic review and meta-analysis. J Thorac Cardiovasc Surg. 2011;141:1305-1312.

9. Megens MR, Churilov L, Thijs V. New-Onset Atrial Fibrillation After Coronary Artery Bypass Graft and Long-Term Risk of Stroke: A Meta-Analysis. J Am Heart Assoc. 2017;6.

10. Lin MH, Kamel $\mathrm{H}$, Singer DE, Wu YL, Lee M, Ovbiagele B. Perioperative/Postoperative Atrial Fibrillation and Risk of Subsequent Stroke and/or Mortality. Stroke. 2019;50:1364-1371.

11. Eikelboom R, Sanjanwala R, Le M-L, Yamashita MH, Arora RC. Post-operative atrial fibrillation after cardiac surgery: a systematic review and meta-analysis. The Annals of Thoracic Surgery. 2020.

12. Kosmidou I, Chen S, Kappetein AP, et al. New-Onset Atrial Fibrillation After PCI or CABG for Left Main Disease: The EXCEL Trial. J Am Coll Cardiol. 2018;71:739-748.

13. Filardo G, Ailawadi G, Pollock BD, et al. Postoperative atrial fibrillation: Sex-specific characteristics and effect on survival. The Journal of Thoracic and Cardiovascular Surgery. 2020;159:1419-1425.e1411.

14. Schwann TA, Al-Shaar L, Engoren MC, et al. Effect of new-onset atrial fibrillation on cause-specific late mortality after coronary artery bypass grafting surgery $\dagger$. European Journal of Cardio-Thoracic Surgery. 2018;54:294-301.

15. Wells G. The Newcastle-Ottawa Scale (NOS) for assessing the quality of nonrandomised studies in meta-analysis. http://www, ohri. ca/programs/clinical_epidemiology. oxford. htm. 2004.

16. Viechtbauer W. Conducting meta-analyses in $\mathrm{R}$ with the metafor package. Journal of statistical software. 2010;36:1-48. 
17. Schwarzer G, Carpenter JR, Rücker G. Meta-analysis with R: Springer; 2015

18. Higgins JP, Thompson SG, Deeks JJ, Altman DG. Measuring inconsistency in metaanalyses. Bmj. 2003;327:557-560.

19. Liberati A, Altman DG, Tetzlaff J, et al. The PRISMA statement for reporting systematic reviews and meta-analyses of studies that evaluate health care interventions: explanation and elaboration. Journal of clinical epidemiology. 2009;62:e1-e34.

20. Hutton B, Salanti G, Caldwell DM, et al. The PRISMA extension statement for reporting of systematic reviews incorporating network meta-analyses of health care interventions: checklist and explanations. Annals of internal medicine. 2015;162:777784.

21. Heijman J, Muna AP, Veleva T, et al. Atrial myocyte NLRP3/CaMKII nexus forms a substrate for post-operative atrial fibrillation. Circulation Research. 2020.

22. Dobrev D, Aguilar M, Heijman J, Guichard JB, Nattel S. Postoperative atrial fibrillation: mechanisms, manifestations and management. Nat Rev Cardiol. 2019; 16:417-436.

23. Borger MA, Mansour MC, Levine RA. Atrial Fibrillation and Mitral Valve Prolapse: Time to Intervene? Journal of the American College of Cardiology. 2019;73:275.

24. Makkar RR, Thourani VH, Mack MJ, et al. Five-Year Outcomes of Transcatheter or Surgical Aortic-Valve Replacement. N Engl J Med. 2020;382:799-809.

25. Barbanti M, Tamburino C, D'Errigo P, et al. Five-Year Outcomes of Transfemoral Transcatheter Aortic Valve Replacement or Surgical Aortic Valve Replacement in a Real World Population: Final Results From the OBSERVANT Study. Circulation: Cardiovascular Interventions. 2019;12:e007825.

26. Jørgensen TH, Thyregod HG, Tarp JB, Svendsen JH, Søndergaard L. Temporal changes of new-onset atrial fibrillation in patients randomized to surgical or transcatheter aortic valve replacement. Int J Cardiol. 2017;234:16-21.

27. Kato M, Saitoh M, Kawamura T, et al. Postoperative atrial fibrillation is associated with delayed early rehabilitation after heart valve surgery: a multicenter study. Phys Ther Res. 2019;22:1-8.

28. Farouk Musa A, Quan CZ, Xin LZ, et al. A retrospective study on atrial fibrillation after coronary artery bypass grafting surgery at The National Heart Institute, Kuala Lumpur. F1000Res. Vol 72018:164.

29. Carter-Storch R, Dahl JS, Christensen NL, et al. Postoperative atrial fibrillation after aortic valve replacement is a risk factor for long-term atrial fibrillation. Interact Cardiovasc Thorac Surg. 2019;29:378-385.

30. Hernández-Leiva E, Alvarado $\mathrm{P}$, Dennis RJ. Postoperative Atrial Fibrillation: Evaluation of its Economic Impact on the Costs of Cardiac Surgery. Braz J Cardiovasc Surg. 2019;34:179-186.

31. Fernandez FG, Shahian DM, Kormos R, et al. The society of thoracic surgeons national database 2019 annual report. The Annals of Thoracic Surgery. 2019;108:1625-1632.

32. Aranki SF, Shaw DP, Adams DH, et al. Predictors of atrial fibrillation after coronary artery surgery: current trends and impact on hospital resources. Circulation. 1996;94:390-397.

33. Makkar RR, Thourani VH, Mack MJ, et al. Five-year outcomes of transcatheter or surgical aortic-valve replacement. New England Journal of Medicine. 2020;382:799. 809.

34. Borger MA, Raschpichler M, Makkar R. Repeat Aortic Valve Surgery or Transcatheter Valve-in-Valve Therapy: We Need a Randomized Trial. J Am Coll Cardiol. 2020;76:500-502. 
425

426

427

428
35. Ruan Y, Robinson NB, Naik A, et al. Effect of atrial pacing on post-operative atrial fibrillation following coronary artery bypass grafting: Pairwise and network metaanalyses. International Journal of Cardiology. 2020;302:103-107. 


\section{FIGURE TITLES}

Figure 1. PRISMA Flow Diagram.

Figure 2. Forest plot for peri-operative mortality.

Figure 3. Sub-group analysis of recent studies in peri-operative mortality (before and after 2010)

Figure 4. Sub-group analysis of rhythm monitoring in peri-operative mortality: comparison between continuous monitoring in intensive care unit and irregular electrocardiogram (ECG) until discharge vs. continuous monitoring during entire hospital stay.

Figure 5. Sub-group analysis of peri-operative mortality: comparison between type of surgeries (CABG; $\mathrm{CABG}$ and valve surgery; valve surgery).

Figure 6. Graphical Abstract.

Figure 7. Central Picture. 


\section{FIGURE LEGENDS}

Figure 1. Preferred Reporting Items for Systematic Reviews and Meta-Analyses flow diagram.

Figure 2. Forest plot showing pooled rates of peri-operative mortality in patients with post-operative atrial fibrillation (POAF) versus no POAF. POAF compared with no POAF was associated with increased peri-operative mortality. Abbreviations: AVR= aortic valve replacement, $\mathrm{CABG}=$ coronary arterial bypass grafting, $\mathrm{CI}=$ confidence interval, $\mathrm{MVR}=$ mitral valve replacement, $\mathrm{OR}=$ odds ratio.

Figure 3. Forest plot for subgroup analysis of peri-operative mortality in studies published prior to the year 2010 and studies published after the year 2010. Abbreviations: AVR= aortic valve replacement, $\mathrm{CABG}=$ coronary arterial bypass grafting, $\mathrm{CI}=$ confidence interval, $\mathrm{MVR}=$ mitral valve replacement, $\mathrm{OR}=$ odds ratio

Figure 4. Forest plot for subgroup analysis of rhythm monitoring type on peri-operative mortality (continuous monitoring in intensive care unit and irregular electrocardiogram (ECG) until discharge vs. continuous monitoring during entire hospital stay). Abbreviations: $\mathrm{CI}=$ confidence interval, $\mathrm{OR}=$ odds ratio.

Figure 5. Sub-group analysis of peri-operative mortality: comparison between type of surgeries (CABG; $\mathrm{CABG}$ and valve surgery; valve surgery). Abbreviations: $\mathrm{CABG}=$ coronary arterial bypass grafting, $\mathrm{CI}=$ confidence interval, $\mathrm{OR}=$ odds ratio. 
Figure 6. Graphical Abstract. POAF after cardiac surgery appears to be associated with increased occurrence of peri-operative mortality, peri-operative stroke, peri-operative myocardial infarction, peri-operative acute renal failure, hospital length of stay, intensive care unit length of stay, long-term mortality, long-term stroke and long-standing persistent atrial fibrillation.

Figure 7. Central Picture. Outcomes of POAF compared with no POAF in cardiac surgery. 
Table 1: Outcomes summary.

\begin{tabular}{|c|c|c|c|c|c|c|}
\hline Outcomes & Studies & Patients & $\begin{array}{l}\text { Measured } \\
\text { estimate }\end{array}$ & Effect estimate & $\begin{array}{l}\text { Heterogeneity } \\
\qquad\left(\operatorname{I\wedge }^{\wedge}\right)\end{array}$ & Higher in \\
\hline \multicolumn{7}{|l|}{$\begin{array}{l}\text { Peri-operative } \\
\text { outcomes }\end{array}$} \\
\hline Mortality & 34 & 171563 & OR & $\begin{array}{c}1.92[1.58 \\
2.33], P<0.0001\end{array}$ & $80.0 \%, P<0.001$ & POAF \\
\hline Stroke & 35 & 179158 & OR & $\begin{array}{c}2.17 \text { [1.90; } \\
2.49], P<0.0001\end{array}$ & $52.2 \%, P<0.001$ & POAF \\
\hline $\begin{array}{l}\text { Myocardial } \\
\text { infarction }\end{array}$ & 20 & 143464 & OR & $\begin{array}{c}1.28[1.06 ; \\
1.54], P=0.0094\end{array}$ & $64.7 \%, P<0.001$ & POAF \\
\hline Acute renal failure & 22 & 139663 & OR & $\begin{array}{c}2.74[2.42 ; \\
3.11], \mathrm{P}<0.0001\end{array}$ & $61.8 \%, P<0.001$ & POAF \\
\hline $\begin{array}{l}\text { Length of hospital } \\
\text { stay }\end{array}$ & 34 & 222442 & SMD & $\begin{array}{c}0.80[0.53 ; \\
1.07], P<0.0001\end{array}$ & $99.6 \%, P<0.001$ & POAF \\
\hline $\begin{array}{l}\text { Intensive care unit } \\
\text { stay }\end{array}$ & 15 & 75529 & SMD & $\begin{array}{c}0.55[0.24 ; \\
0.86], P<0.0001\end{array}$ & $99.5 \%, \mathrm{P}<0.001$ & POAF \\
\hline \multicolumn{7}{|l|}{$\begin{array}{l}\text { Long term } \\
\text { outcomes }\end{array}$} \\
\hline Mortality & 28 & ----- & IRR & $\begin{array}{c}1.54[1.40 ; \\
1.69], P<0.0001\end{array}$ & $83.8 \%, P<0.001$ & POAF \\
\hline Stroke & 5 & ----- & IRR & $\begin{array}{c}1.33[1.21 ; \\
1.46], P<0.0001\end{array}$ & $0.0 \%, P=5321$ & POAF \\
\hline $\begin{array}{l}\text { Long-standing } \\
\text { persistent atrial } \\
\text { fibrillation }\end{array}$ & 10 & ----- & IRR & $\begin{array}{c}4.73[3.36 ; \\
6.66], P<0.0001\end{array}$ & $70.6 \%, P=0.0014$ & POAF \\
\hline
\end{tabular}

$\mathrm{IRR}=$ incidence rate ratio; $\mathrm{OR}=$ odds ratio $\mathrm{POAF}=$ post-operative atrial fibrillation;

$\mathrm{SMD}=$ standard mean difference. 
Figure 1. PRISMA Flow Diagram.

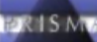

PRISMA Flow Diagram
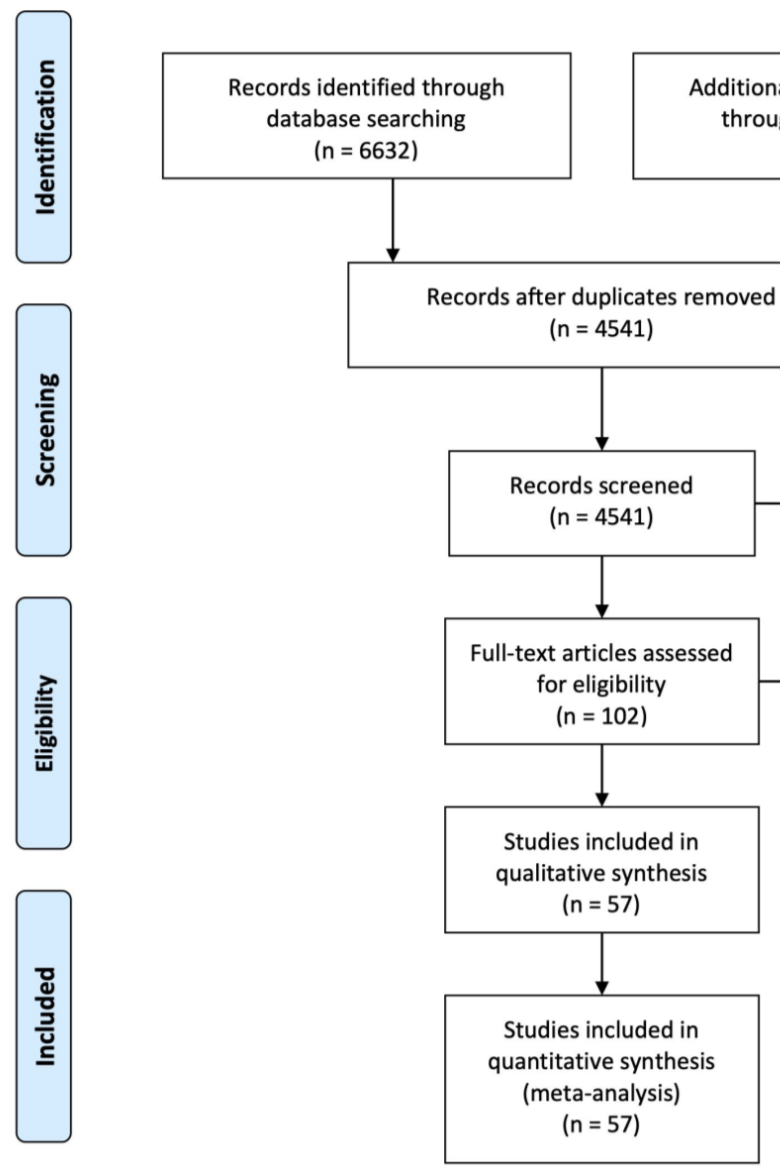

Records excluded based on title or abstract $(n=4439)$

Full-text articles excluded with reasons:

- Not English Studies $(n=13)$

- Review $(n=17)$

- Studies irrelevant to study question ( $n=15)$ 
Figure 2. Forest plot for peri-operative mortality.

\section{Peri-operative mortality}

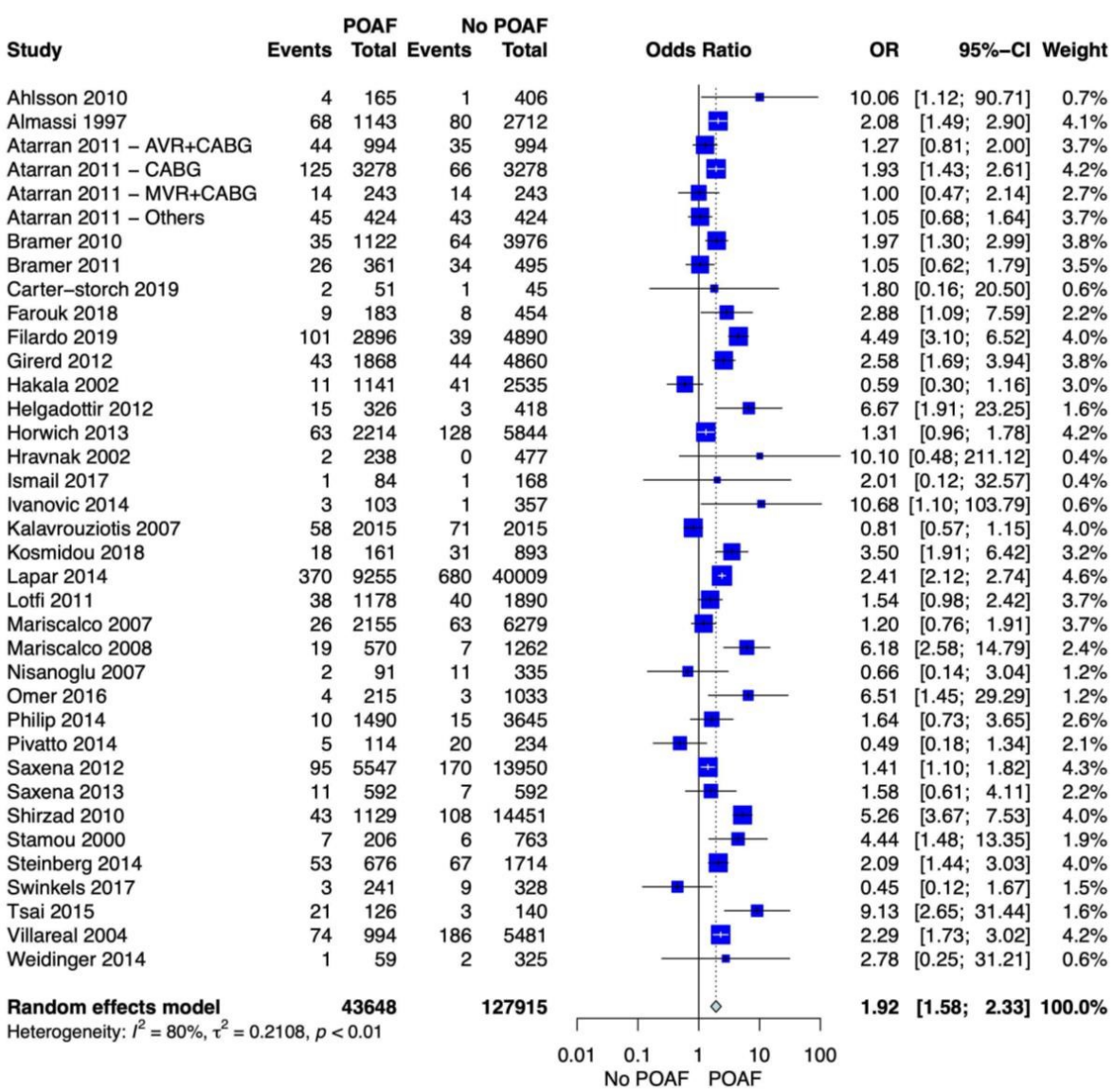


Figure 3. Sub-group analysis of recent studies in peri-operative mortality (before and after 2010).

\section{Peri-operative mortality}

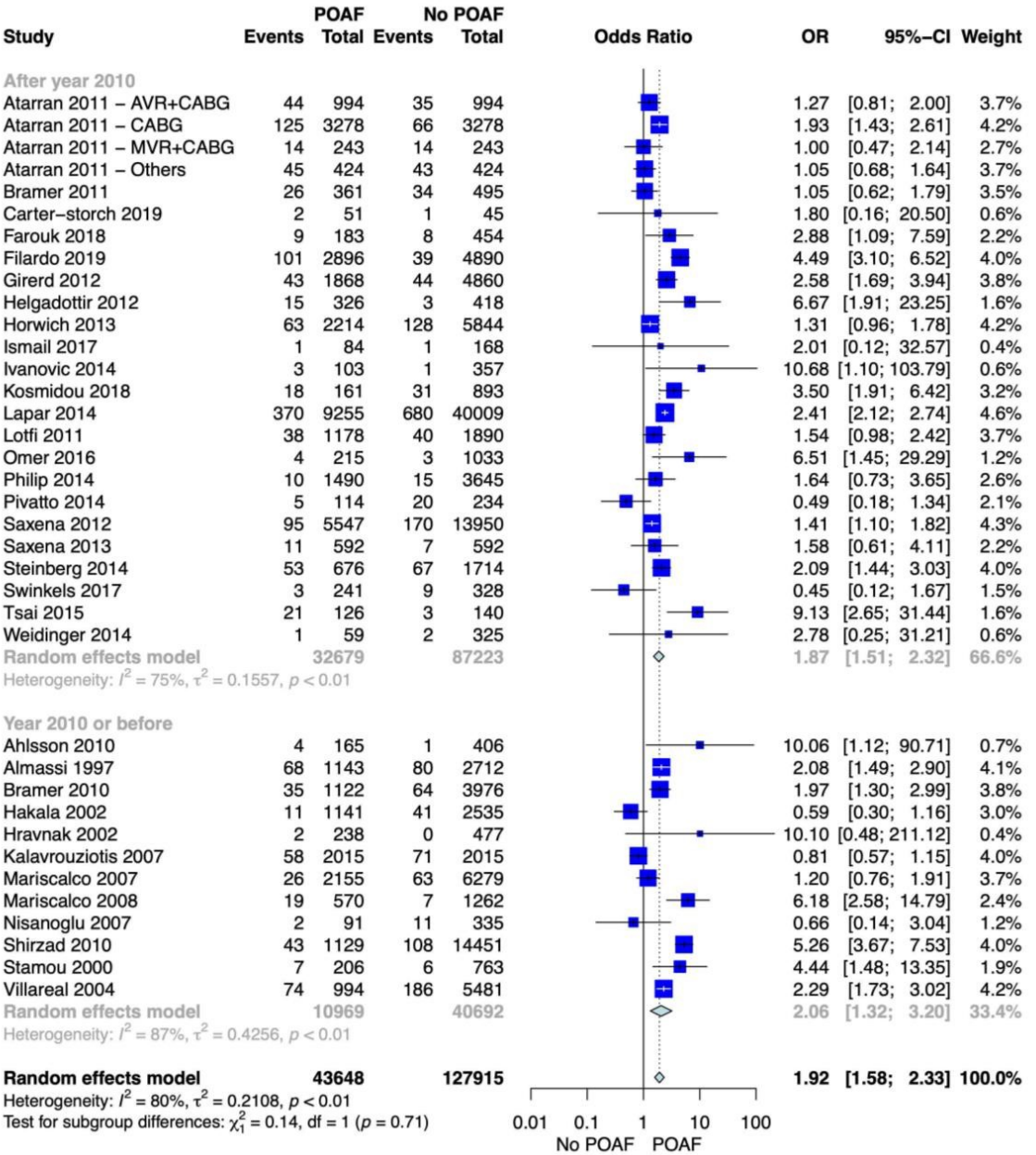


Figure 4. Sub-group analysis of rhythm monitoring in peri-operative mortality: comparison between continuous monitoring in intensive care unit and irregular electrocardiogram (ECG) until discharge vs. continuous monitoring during entire hospital stay.

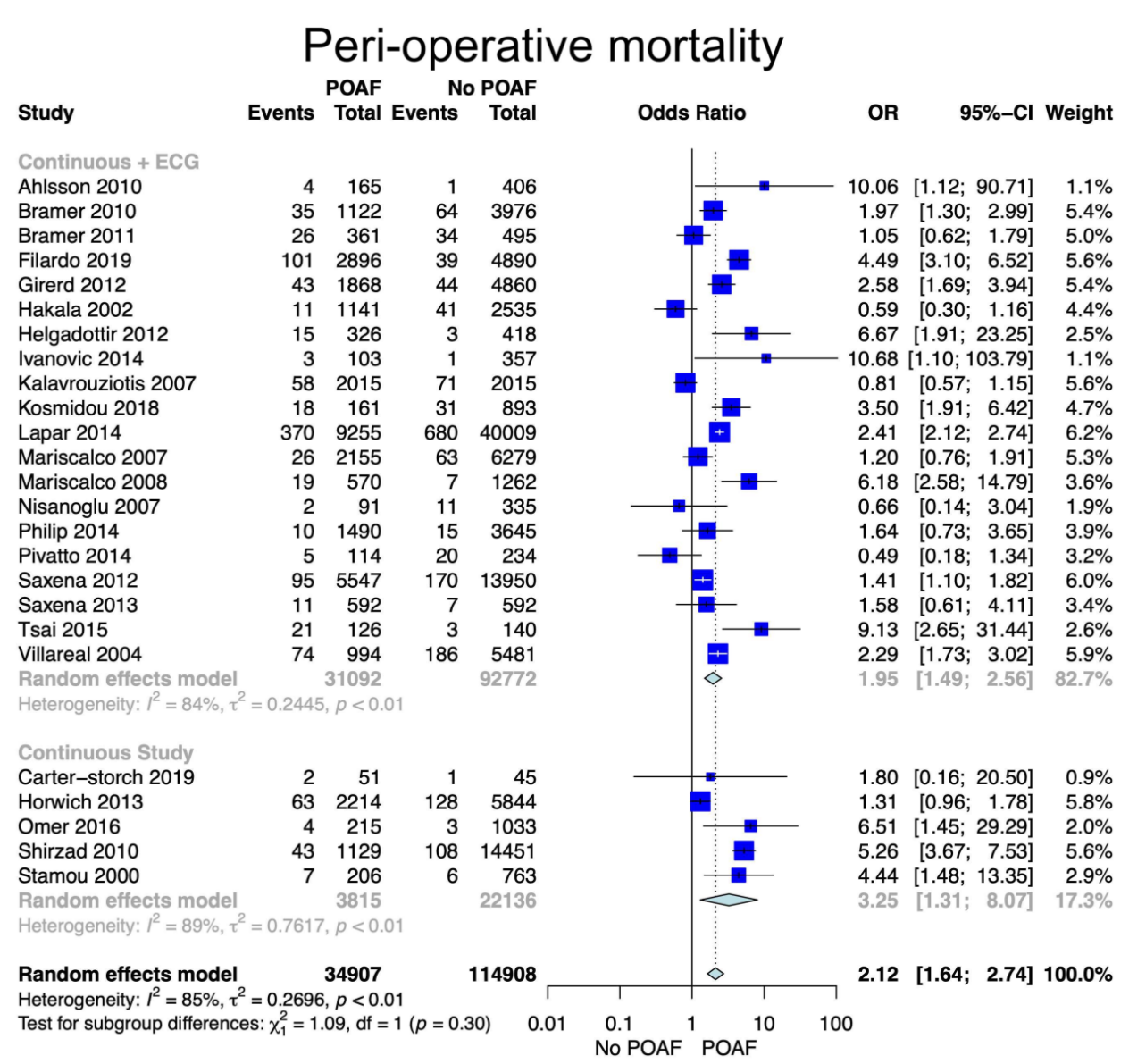


Figure 5. Sub-group analysis of peri-operative mortality: comparison between type of surgeries (CABG; CABG and valve surgery; valve surgery).

\section{Peri-operative mortality}

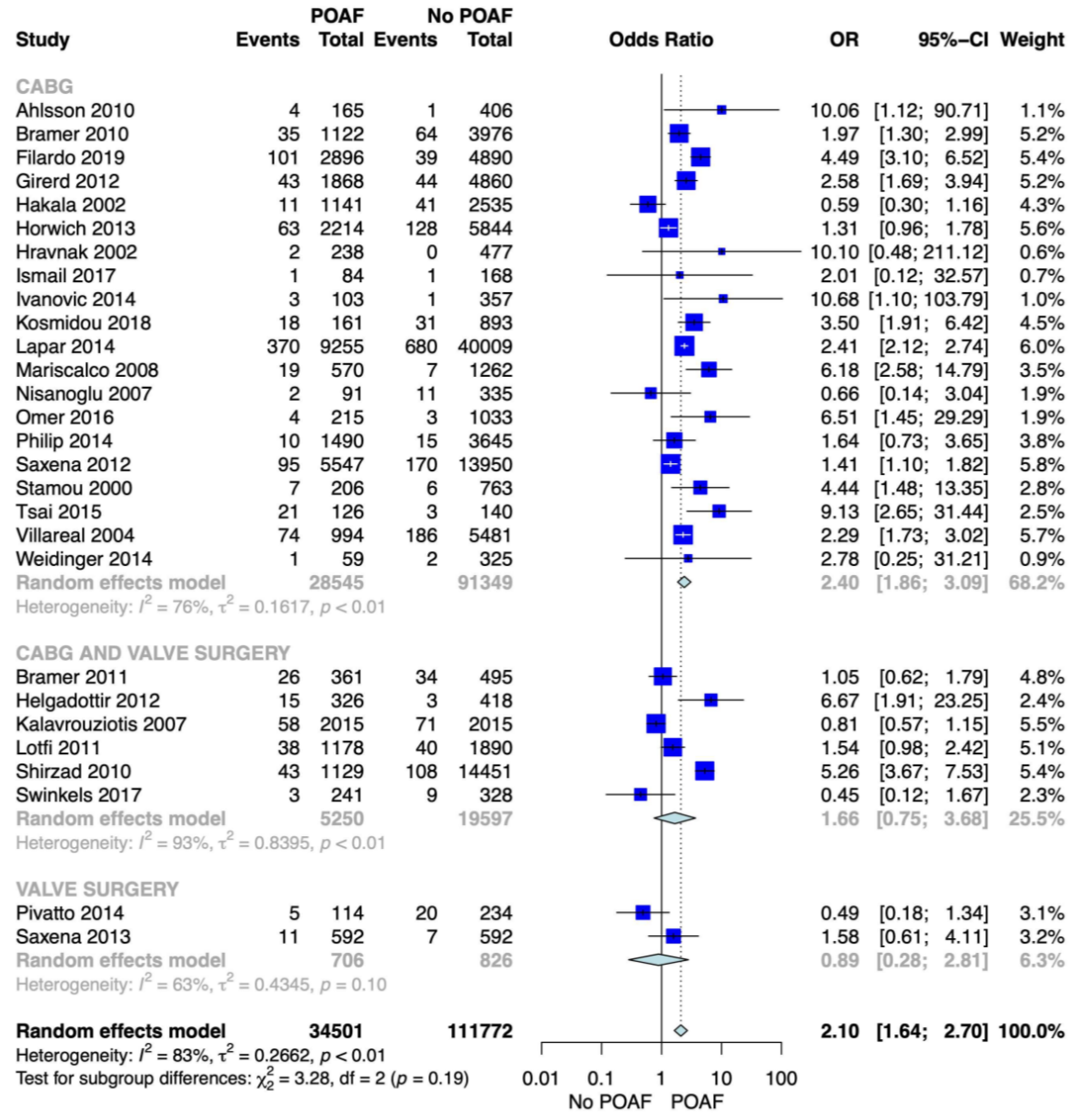


Figure 6. Graphical Abstract.

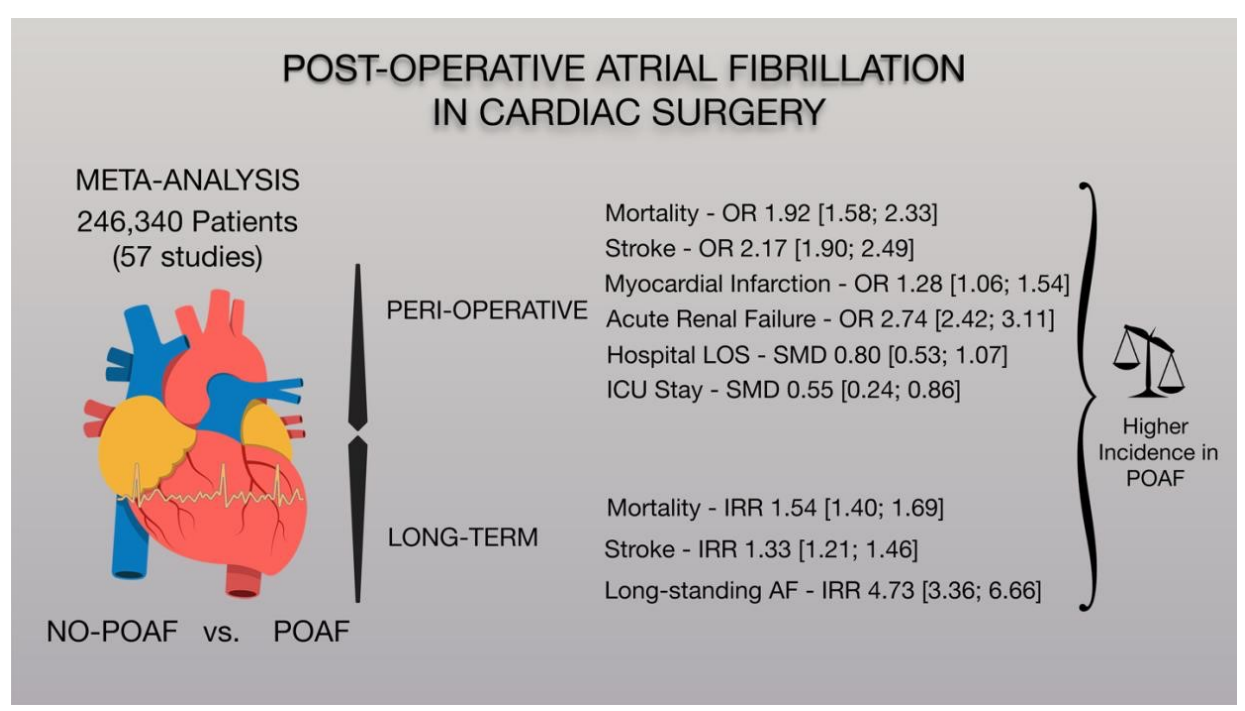


Figure 7. Central Picture.

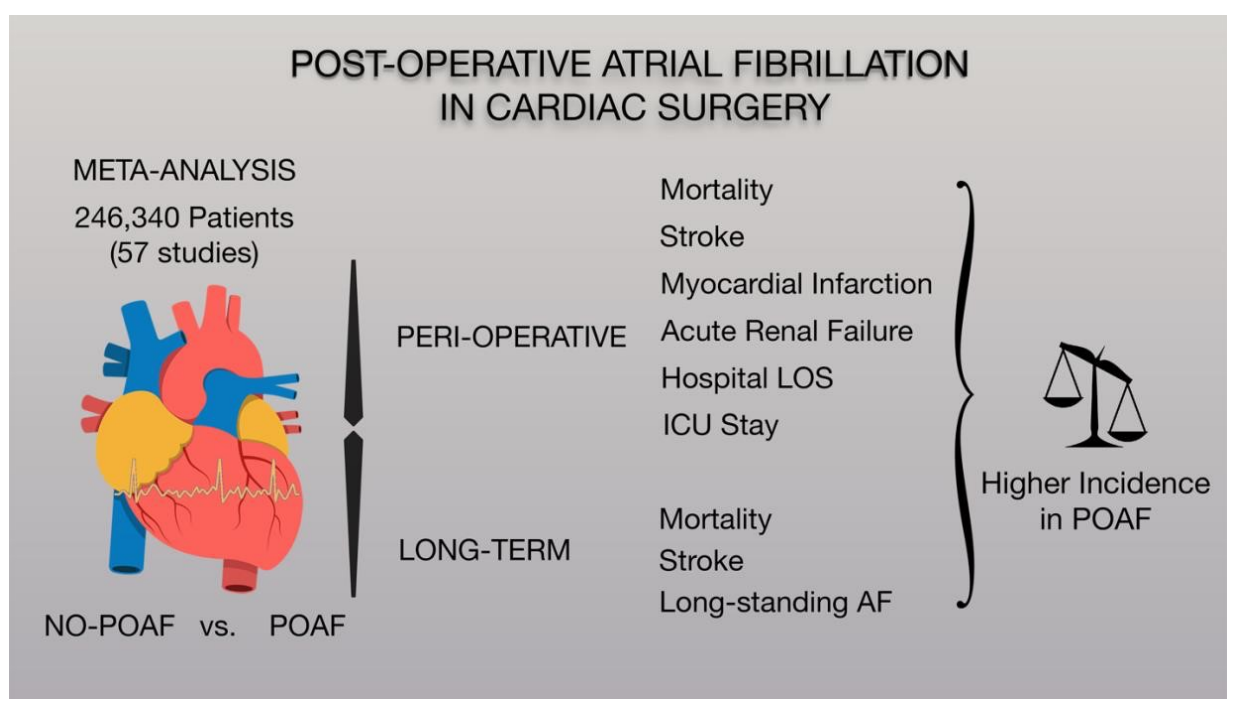




\title{
4.2. Letter of Acceptance
}

\author{
Date: $\quad$ Mar 12, 2021 \\ To: $\quad$ "Torsten Doenst" doenst@med.uni-jena.de;benjamin.may@med.uni-jena.de \\ cc: rakesh arora (rakeshcarora@gmail.com), stephen.fremes@sunnybrook.ca \\ From: "Journal of Thoracic and Cardiovascular Surgery" jtcvs@aats.org \\ Subject: Acceptance of your Submission JTCVS-20-3301R2
}

\author{
The Journal of \\ Thoracic and Cardiovascular Surgery \\ Richard D. Weisel, MD, Editor
}

Re: Original Manuscript JTCVS-20-3301R2

Atrial Fibrillation after Cardiac Surgery - A Systematic Review and Meta-Analysis

$\underline{\text { http://jtcvs.editorialmanager.com }}$

Dear Dr. Doenst:

The editorial staff of The Journal of Thoracic and Cardiovascular Surgery is pleased to inform you that, after careful review, your Original Manuscript "Atrial Fibrillation after Cardiac Surgery - A Systematic Review and Meta-Analysis" has been accepted for publication.

You will receive an electronic copyright form and electronic page proofs directly from Elsevier Science Publishing. Once received, please return these proofs with all necessary corrections to Elsevier within 48 hours.

Thank you for your interest in and support of The Journal of Thoracic and Cardiovascular Surgery.

Sincerely,

Richard D. Weisel, MD, Edito

Rakesh C. Arora, MD, PhD, Associate Editor

Stephen E. Fremes, MD, MSc, Associate Statistical Editor

The Journal of Thoracic and Cardiovascular Surgery

American Association for Thoracic Surgery

800 Cummings Center, Suite 350-V

Beverly, MA 01915

Telephone: 978-252-2200 Ext. 549

E-mail: jtcvs@aats.org 


\section{Dis cussion}

The meta-analysis suggests that POAF in cardiac surgery is associated with an increased occurrence of most short and long-term cardiovascular adverse events. Specifically, POAF appears to be associated with peri-operative mortality, peri-operative stroke, peri-operative myocardial infarction, peri-operative acute renal failure and long-term mortality, long-term stroke, long-standing persistent $\mathrm{AF}$, as well as hospital length of stay and intensive care unit length of stay. We addressed the specific aspects of the meta-analysis, its strengths and limitations in the discussion of the original manuscript in the last section. I here discuss the general meaning of the associations found in our meta-analysis and meta-regression.

These results suggest that POAF should no longer be understood as transitory, self-sufficient and potentially clinical insignificant complication in cardiac surgery. The main concern arising from these findings shows that the cardiovascular community can benefit from better surgical outcomes if they comprehend the underlying mechanism of this condition. A key question addresses the role of POAF as an indicator of a particular combination of risk factors or as the main causative element itself.

\subsection{Causality Aspects}

A key question is whether POAF is a cause or merely an indicator of the described complications. It is conceivable that POAF occurs most frequently in patients with comorbidities and is therefore associated with increased mortality. It will currently be impossible to provide a definitive answer to this question because of the lack of an ideal control group of patients not having undergone surgery with otherwise the same demographic characteristics.

Anyway, cardiac surgery patients have higher incidence of POAF compared with those undergoing non-cardiac surgery (Christians et al. 2001, Villareal et al. 2004, Echahidi et al. 2008, Turagam et al. 2016). In this context, a certain degree of causality may be expected, mainly based on an exposure-response relationship: the incidence of POAF increases as the cardiac surgical approach becomes more invasive (Mihos et al. 2013, Tanawuttiwat et al. 2014). This notion is supported also in randomized trials comparing CABG and PCI where 
similar patients in both groups show an increased incidence of POAF between procedures based on its level of invasiveness (i.e., CABG compared with PCI procedure $-18.0 \%$ versus $0.1 \%$ ) (Stone et al. 2016, Kosmidou et al. 2018). These findings reinforce the idea that reducing the degree of operative trauma may result in the reduction of POAF incidence. Thus, minimally invasive approaches may have to be investigated for their ability to reduce this adverse event. Observational evidence suggests that minimally-invasive procedures may indeed be associated with lower rates of POAF in comparison with the traditional approach (Tabata et al. 2008, Murzi et al. 2012, Glauber et al. 2013, Doenst und Lamelas 2017, Doenst et al. 2020, Faerber et al. 2020).

\subsection{Race and Sex Diffe rence}

POAF also appears to be influenced by differences in the genetic background. For instance, POAF was observed to be a stronger predictor of operative mortality in Black individuals compared with White patients undergoing elective CABG (Efird et al. 2013). Black patients are less likely to develop POAF following CABG than Whites despite Black patients having an increased prevalence of POAF risk factors, such as age, hypertension, obesity and heart failure (Lahiri et al. 2011, Sun et al. 2011, Rader et al. 2011, Efird et al. 2013).

Male gender is also one of the possible risk factors described in the literature. The apparent protective effect of female sex shows not to be a mere coincidence, because male sex is frequently identified as an independent risk factor for POAF in CABG patients (Zacharias et al. 2005, Filardo et al. 2009, Alam et al. 2013, Almassi et al. 2019).

The race influence and how female sex protects against POAF are statements that require further research. Sex-specific studies have historically been missing from the evidence base but have been called for in recent years to help address continuing sex-related disparities in health care issues and key outcomes (Girardi et al. 2019, Gaudino et al. 2020a, Gaudino et al. 2020b). 


\subsection{Long-s tanding Atrial Fibrillation as a Cons equence of POAF}

An important point of our meta-analysis is the fact that it did not only show an association with short-term outcomes, but especially with long-term clinical adverse events. One of these implications that deserves specific attention is the fact that the meta-analysis demonstrates increased occurrence of long-standing AF in individuals that developed POAF (Ahlsson et al. 2010, Pillarisetti et al. 2014, Melduni et al. 2015, Tulla et al. 2015, Konstantino et al. 2016, Lee et al. 2017, Park et al. 2017, Carter-Storch et al. 2019, Thorén et al. 2020). Patients with POAF can present increased incidence of AF not only compared with patients without POAF but also compared with matched presumably healthy controls (Thorén et al. 2020). This increase in AF compared with controls persisted over time and was valid after more than 10 years of follow-up. On the other hand, the non-POAF cohort showed no increase in AF beyond the first postoperative year (Thorén et al. 2020). This finding supports the notion that a certain substrate for the development of AF is present at an increased prevalence in those patients developing POAF. Thus, surgical trauma triggers AF earlier than it would appear naturally anyway (Dobrev et al. 2019). The fact that POAF may lead to chronic AF then of course introduces all adverse events associated with chronic AF into the POAF arena. Patients with chronic AF show a dramatic increase in the incidence of pathologies such as stroke and heart failure (Chen et al. 2018, Vintila et al. 2019). Based on the economic, health and social impact from atrial fibrillation, these results are certainly alarming and accentuate the harmful potential of POAF (Chen et al. 2018, Vintila et al. 2019). Therefore, it is clear that POAF is a clinical entity that deserves attention and probably the investment of efforts to combat it through new medical therapies, new surgical approaches and new therapeutic alternatives.

\subsection{Manage ment and Possible Treatments}

\subsubsection{Medication}

Nowadays, perioperative beta-blocker treatment is the main pharmacologic therapy with the objective to reduce rates of POAF (Echahidi et al. 2008, Dobrev et al. 2019). Other therapies such as amiodarone, verapamil, diltiazem, and digoxin are used less frequently and are generally less effective (Buckley et al. 2007). Due to the low efficacy of traditional drug therapy, new solutions have been proposed in order to act not only in the causative mechanism, but also in the prophylaxis of possible deleterious effects. 
In this context, the use of anticoagulants proved to be a potential treatment in POAF due to its classic use in chronic atrial fibrillation. Recently, El-Chami and colleagues analyzed the connection between anticoagulation and survival in cardiac surgery patients with POAF, showing mortality reduction in patients treated with warfarin, after adjusting for age, sex, and medical comorbidities (El-Chami et al. 2010).

Generally, anticoagulation in atrial fibrillation has been aimed at reducing stroke risk and minimizing other side effects. However, anticoagulation in patients with POAF is an unexplored topic. No guidelines provide specific recommendations for initiation of anticoagulation for POAF in the post-cardiac surgery population (Macle et al. 2016, Kirchhof et al. 2016). The majority of evidence for anticoagulation in AF emerges mostly from the nonsurgical community, which have a substantially different risk profile compared to surgical patients in terms of bleeding risk and, above all, as possible trigger for AF. Accordingly, as the profile of patients is different and especially the etiology of AF, it is difficult to draw conclusions about the therapeutic efficacy of these drugs. Thus, undoubtedly the role of anticoagulation in POAF is a topic that needs to be explored with an accurate study design through a randomized clinical approach.

In the long term, for the patient with long-standing persistent atrial fibrillation after cardiac surgery, the use of Novel Oral Anticoagulants (NOAC) may be plausible, as a number of studies have shown NOACs reduce bleeding risk and other severe complications in comparis on with warfarin (Hicks et al. 2016, Aimo et al. 2018). However, no data has shown the effect of NOACs in the specific population of patients developing POAF.

\subsubsection{Bi-atrial Pacing}

Bi-atrial pacing has emerged as a promising approach to reduce the incidence of POAF. The rationale is that the electric maintenance of atrio-ventricular synchrony has shown to reduce the incidence of atrial fibrillation by suppressing premature atrial complexes and runs of supraventricular re-entry rhythm (Saksena et al. 1996, Gillis et al. 1999). 
A recent work on the topic, showed in a pairwise and network meta-analysis involving 14 trials that bi-atrial pacing, compared to other pacing modalities, is associated with lower rates of POAF following CABG (Ruan et al. 2020). These findings demonstrate that an effective therapy for POAF is plausible and accessible. However, bi-atrial pacing has not yet been accepted in routine practice, possibly for its technical need for the tedious need to place two epicardial pacemaker wires. We are currently starting a trial in our Department to assess the impact of bi-atrial pacing and the possible therapeutic impact of atrial cardioversion on the incidence and clinical course of POAF (Defi-Pace trial). Other trials are currently ongoing in this field.

\subsection{Current Prospective Trials on POAF}

\subsubsection{CABG-AF Trial}

CABG-AF is a multicenter trial where study patients undergoing $\mathrm{CABG}$, without previous history of atrial fibrillation or other complex rhythm disorders are receiving an event-recorder implantation at the end of surgery. Their heart rhythms are being continuously monitored for up to 3 years. Data concerning the development of atrial fibrillation, atrial fibrillation burden, atrial fibrillation density, number and length of atrial fibrillation, episodes, silent vs. symptomatic episodes, stroke and mortality will be collected and evaluated. Our center is one of the four surgical centers participating in the study within the GermaN HeaRTS Network.

\subsubsection{PACES Trial}

The Anticoagulation for New-Onset Post-Operative Atrial Fibrillation after CABG (PACES) trial [NCT04045665] is a multicenter randomized controlled trial with the aim to evaluate the effectiveness (prevention of thromboembolic events) and safety (major bleeding) of adding oral anticoagulation (OAC) to background antiplatelet therapy in patients who develop newonset post-operative atrial fibrillation (POAF) after isolated coronary artery bypass graft (CABG) surgery. In the trial, 3200 patients are been randomized in 2 arms:

- OAC-based strategy (experimental arm): OAC with vitamin K antagonist (VKA) with international normalized ratio (INR) target 2-3 or any approved direct oral anticoagulant (apixaban, rivaroxaban, edoxaban or dabigatran) in addition to 
background antiplatelet therapy with aspirin $75-325 \mathrm{mg}$ once-daily or a P2Y12-inhibitor (clopidogrel or ticagrelor);

- Antiplatelet-only strategy (control arm): with aspirin 75-325mg once-daily or a P2Y12inhibitor (clopidogrel or ticagrelor).

The primary outcome of the study is a composite of death, stroke, transient ischemic attack, myocardial infarction, systemic arterial thromboembolism or venous thromboembolism. 


\section{Conclusions}

POAF after cardiac surgery appears to be associated with increased occurrence of a plethora of cardiovascular adverse events. While a directly causal relationship between POAF and these adverse cardiovascular events cannot be totally established. The information represents an important milestone for future hypotheses about etiology from POAF and for designing randomized trials addressing its prevention/treatment. 


\section{Bibliography Refe rences}

Ahlsson A, Fengsrud E, Bodin L, Englund A. 2010. Postoperative atrial fibrillation in patients undergoing aortocoronary bypass surgery carries an eightfold risk of future atrial fibrillation and a doubled cardiovascular mortality. Eur J Cardiothorac Surg, 37 (6):1353-1359.

Aimo A, Giugliano RP, De Caterina R. 2018. Non-Vitamin K Antagonist Oral Anticoagulants for Mechanical Heart Valves: Is the Door Still Open? Circulation, 138 (13):1356-1365.

Alam M, Lee V-V, Elayda MA, Shahzad SA, Yang EY, Nambi V, Jneid H, Pan W, Coulter S, Wilson JM, Ramanathan KB, Ballantyne CM, Virani SS. 2013. Association of gender with morbidity and mortality after isolated coronary artery bypass grafting. A propensity score matched analysis. International Journal of Cardiology, 167 (1):180 184.

Almassi GH, Hawkins RB, Bishawi M, Shroyer AL, Hattler B, Quin JA, Collins JF, Bakaeen FG, Ebrahimi R, Grover FL. 2019. New-onset postoperative atrial fibrillation impact on 5-year clinical outcomes and costs. The Journal of Thoracic and Cardiovascular Surgery.

Almassi GH, Schowalter T, Nicolosi AC, Aggarwal A, Moritz TE, Henderson WG, Tarazi R, Shroyer AL, Sethi GK, Grover FL, Hammermeister KE. 1997. Atrial fibrillation after cardiac surgery: a major morbid event? Ann Surg, 226 (4):501-511; discussion 511503.

Amar D, Zhang H, Miodownik S, Kadish AH. 2003. Competing autonomic mechanisms precede the onset of postoperative atrial fibrillation. J Am Coll Cardiol, 42 (7):12621268 .

Andrade J, Khairy P, Dobrev D, Nattel S. 2014. The clinical profile and pathophysiology of atrial fibrillation: relationships among clinical features, epidemiology, and mechanisms. Circ Res, 114 (9):1453-1468.

Aranki SF, Shaw DP, Adams DH, Rizzo RJ, Couper GS, VanderVliet M, Collins JJ, Jr., Cohn LH, Burstin HR. 1996. Predictors of atrial fibrillation after coronary artery surgery. Current trends and impact on hospital resources. Circulation, 94 (3):390-397.

Argalious M, Motta P, Khandwala F, Samuel S, Koch CG, Gillinov AM, Yared JP, Starr NJ, Bashour CA. 2005. "Renal dose" dopamine is associated with the risk of new-onset atrial fibrillation after cardiac surgery. Crit Care Med, 33 (6):1327-1332. 
Auer J, Weber T, Berent R, Puschmann R, Hartl P, Ng CK, Schwarz C, Lehner E, Strasser U, Lassnig E, Lamm G, Eber B. 2004. A comparison between oral antiarrhythmic drugs in the prevention of atrial fibrillation after cardiac surgery: the pilot study of prevention of postoperative atrial fibrillation (SPPAF), a randomized, placebo-controlled trial. Am Heart J, 147 (4):636-643.

Banach M, Rysz J, Drozdz JA, Okonski P, Misztal M, Barylski M, Irzmanski R, Zaslonka J. 2006. Risk factors of atrial fibrillation following coronary artery bypass grafting: a preliminary report. Circ J, 70 (4):438-441.

Buckley MS, Nolan Jr. PE, Slack MK, Tisdale JE, Hilleman DE, Copeland JG. 2007. Amiodarone Prophylaxis for Atrial Fibrillation After Cardiac Surgery: Meta-Analysis of Dose Response and Timing of Initiation. Pharmacotherapy: The Journal of Human Pharmacology and Drug Therapy, 27 (3):360-368.

Carter-Storch R, Dahl JS, Christensen NL, Pecini R, Søndergård EV, Øvrehus KA, Møller JE. 2019. Postoperative atrial fibrillation after aortic valve replacement is a risk factor for long-term atrial fibrillation. Interact Cardiovasc Thorac Surg, 29 (3):378-385.

Chen LY, Chung MK, Allen LA, Ezekowitz M, Furie KL, McCabe P, Noseworthy PA, Perez MV, Turakhia MP. 2018. Atrial Fibrillation Burden: Moving Beyond Atrial Fibrillation as a Binary Entity: A Scientific Statement From the American Heart Association. Circulation, 137 (20):e623-e644.

Christians KK, Wu B, Quebbeman EJ, Brasel KJ. 2001. Postoperative atrial fibrillation in noncardiothoracic surgical patients. The American journal of surgery, 182 (6):713-715.

Dobrev D, Aguilar M, Heijman J, Guichard JB, Nattel S. 2019. Postoperative atrial fibrillation: mechanisms, manifestations and management. Nat Rev Cardiol, 16 (7):417-436.

Doenst T, Lamelas J. 2017. Do we have enough evidence for minimally-invasive cardiac surgery? A critical review of scientific and non-scientific information. J Cardiovasc Surg (Torino), 58 (4):613-623.

Doenst T, Bargenda S, Kirov H, Moschovas A, Tkebuchava S, Safarov R, Velichkov I, Diab M. 2020. Cardiac Surgery 2019 Reviewed. Thorac Cardiovasc Surg, 68 (5):363-376.

Echahidi N, Pibarot P, O'Hara G, Mathieu P. 2008. Mechanisms, prevention, and treatment of atrial fibrillation after cardiac surgery. Journal of the American College of Cardiology, 51 (8):793-801. 
Efird JT, Davies SW, O'Neal WT, Anderson CA, Anderson EJ, O'Neal JB, Ferguson TB, Chitwood WR, Kypson AP. 2013. The impact of race and postoperative atrial fibrillation on operative mortality after elective coronary artery bypass grafting. European Journal of Cardio-Thoracic Surgery, 45 (2):e20-e25.

El-Chami MF, Kilgo P, Thourani V, Lattouf OM, Delurgio DB, Guyton RA, Leon AR, Puskas JD. 2010. New-onset atrial fibrillation predicts long-term mortality after coronary artery bypass graft. J Am Coll Cardiol, 55 (13):1370-1376.

Faerber G, Tkebuchava S, Scherag A, Bley M, Kirov H, Diab M, Doenst T. 2020. Right MiniThoracotomy for Aortic Plus Mitral with or without Tricuspid Valve Surgery. Thorac Cardiovasc Surg.

Feneck RO, Sherry KM, Withington PS, Oduro-Dominah A. 2001. Comparison of the hemodynamic effects of milrinone with dobutamine in patients after cardiac surgery. $\mathrm{J}$ Cardiothorac Vasc Anesth, 15 (3):306-315.

Filardo G, Hamilton C, Hamman B, Hebeler RF, Grayburn PA. 2009. Relation of Obesity to Atrial Fibrillation After Isolated Coronary Artery Bypass Grafting. The American Journal of Cardiology, 103 (5):663-666.

Filardo G, Ailawadi G, Pollock BD, da Graca B, Phan TK, Thourani V, Damiano RJ. 2020. Postoperative atrial fibrillation: Sex-specific characteristics and effect on survival. The Journal of Thoracic and Cardiovascular Surgery, 159 (4):1419-1425.e1411.

Funk M, Richards SB, Desjardins J, Bebon C, Wilcox H. 2003. Incidence, timing, symptoms, and risk factors for atrial fibrillation after cardiac surgery. Am J Crit Care, 12 (5):424433; quiz 434-425.

Gaudino M, Samadashvili Z, Hameed I, Chikwe J, Girardi LN, Hannan EL. 2020a. Differences in Long-term Outcomes After Coronary Artery Bypass Grafting Using Single vs Multiple Arterial Grafts and the Association With Sex. JAMA Cardiology.

Gaudino M, Andreotti F, Zamparelli R, Castelnuovo AD, Nasso G, Burzotta F, Iacoviello L, Donati MB, Schiavello R, Maseri A, Possati G. 2003. The \&\#x2212;174G/C Interleukin-6 Polymorphism Influences Postoperative Interleukin-6 Levels and Postoperative Atrial Fibrillation. Is Atrial Fibrillation an Inflammatory Complication? Circulation, 108 (10_suppl_1):II-195-II-199.

Gaudino M, Alexander JH, Egorova N, Kurlansky P, Lamy A, Bakaeen F, Hameed I, Di Franco A, Demetres M, Robinson NB, Chikwe J, Lawton JS, Devereaux PJ, Taggart DP, Flather M, Reents W, Boening A, Diegeler A, Girardi LN, Fremes SE, Benedetto U. 
2020b. Sex-related differences in outcomes after coronary artery bypass surgery-A patient-level pooled analysis of randomized controlled trials: rationale and study protocol. J Card Surg, 35 (10):2754-2758.

Gillinov AM, Bagiella E, Moskowitz AJ, Raiten JM, Groh MA, Bowdish ME, Ailawadi G, Kirkwood KA, Perrault LP, Parides MK, Smith RL, 2nd, Kern JA, Dussault G, Hackmann AE, Jeffries NO, Miller MA, Taddei-Peters WC, Rose EA, Weisel RD, Williams DL, Mangusan RF, Argenziano M, Moquete EG, O'Sullivan KL, Pellerin M, Shah KJ, Gammie JS, Mayer ML, Voisine P, Gelijns AC, O'Gara PT, Mack MJ. 2016. Rate Control versus Rhythm Control for Atrial Fibrillation after Cardiac Surgery. N Engl J Med, 374 (20):1911-1921.

Gillis AM, Wyse DG, Connolly SJ, Dubuc M, Philippon F, Yee R, Lacombe P, Rose MS, Kerr CD. 1999. Atrial Pacing Periablation for Prevention of Paroxysmal Atrial Fibrillation. Circulation, 99 (19):2553-2558.

Girardi LN, Leonard JR, Lau C, Ohmes LB, Gambardella I, Iannacone EM, Munjal M, Schwann AN, Gaudino MFL. 2019. Gender-related outcomes after open repair of descending thoracic and thoracoabdominal aortic aneurysms. J Vasc Surg, 69 (4):10281035.e1021.

Glauber M, Miceli A, Gilmanov D, Ferrarini M, Bevilacqua S, Farneti PA, Solinas M. 2013. Right anterior minithoracotomy versus conventional aortic valve replacement: a propensity score matched study. J Thorac Cardiovasc Surg, 145 (5):1222-1226.

Greenberg JW, Lancaster TS, Schuessler RB, Melby SJ. 2017. Postoperative atrial fibrillation following cardiac surgery: a persistent complication. Eur J Cardiothorac Surg, 52 (4):665-672.

Hak Ł, Myśliwska J, Wieckiewicz J, Szyndler K, Siebert J, Rogowski J. 2009. Interleukin-2 as a predictor of early postoperative atrial fibrillation after cardiopulmonary bypass graft (CABG). J Interferon Cytokine Res, 29 (6):327-332.

Heijman J, Guichard JB, Dobrev D, Nattel S. 2018. Translational Challenges in Atrial Fibrillation. Circ Res, 122 (5):752-773.

Hicks T, Stewart F, Eisinga A. 2016. NOACs versus warfarin for stroke prevention in patients with AF: a systematic review and meta-analysis. Open Heart, 3 (1):e000279.

Ho KM, Tan JA. 2009. Benefits and risks of corticosteroid prophylaxis in adult cardiac surgery: a dose-response meta-analysis. Circulation, 119 (14):1853-1866. 
Hogue CW, Jr., Domitrovich PP, Stein PK, Despotis GD, Re L, Schuessler RB, Kleiger RE, Rottman JN. 1998. RR interval dynamics before atrial fibrillation in patients after coronary artery bypass graft surgery. Circulation, 98 (5):429-434.

Ishii Y, Schuessler RB, Gaynor SL, Yamada K, Fu AS, Boineau JP, Damiano RJ, Jr. 2005. Inflammation of atrium after cardiac surgery is associated with inhomogeneity of atrial conduction and atrial fibrillation. Circulation, 111 (22):2881-2888.

Kaireviciute D, Blann AD, Balakrishnan B, Lane DA, Patel JV, Uzdavinys G, Norkunas G, Kalinauskas G, Sirvydis V, Aidietis A, Lip GY. 2010. Characterisation and validity of inflammatory biomarkers in the prediction of post-operative atrial fibrillation in coronary artery disease patients. Thromb Haemost, 104 (1):122-127.

Kirchhof P, Benussi S, Kotecha D, Ahlsson A, Atar D, Casadei B, Castella M, Diener HC, Heidbuchel H, Hendriks J, Hindricks G, Manolis AS, Oldgren J, Popescu BA, Schotten U, Van Putte B, Vardas P, Agewall S, Camm J, Baron Esquivias G, Budts W, Carerj S, Casselman F, Coca A, De Caterina R, Deftereos S, Dobrev D, Ferro JM, Filippatos G, Fitzsimons D, Gorenek B, Guenoun M, Hohnloser SH, Kolh P, Lip GY, Manolis A, McMurray J, Ponikowski P, Rosenhek R, Ruschitzka F, Savelieva I, Sharma S, Suwalski P, Tamargo JL, Taylor CJ, Van Gelder IC, Voors AA, Windecker S, Zamorano JL, Zeppenfeld K. 2016. 2016 ESC Guidelines for the management of atrial fibrillation developed in collaboration with EACTS. Eur J Cardiothorac Surg, 50 (5):e1-e88.

Konstantino Y, Zelnik Yovel D, Friger MD, Sahar G, Knyazer B, Amit G. 2016. Postoperative Atrial Fibrillation Following Coronary Artery Bypass Graft Surgery Predicts LongTerm Atrial Fibrillation and Stroke. Isr Med Assoc J, 18 (12):744-748.

Kosmidou I, Chen S, Kappetein AP, Serruys PW, Gersh BJ, Puskas JD, Kandzari DE, Taggart DP, Morice MC, Buszman PE, Bochenek A, Schampaert E, Pagé P, Sabik JF, 3rd, McAndrew T, Redfors B, Ben-Yehuda O, Stone GW. 2018. New-Onset Atrial Fibrillation After PCI or CABG for Left Main Disease: The EXCEL Trial. J Am Coll Cardiol, 71 (7):739-748.

Lahiri MK, Fang K, Lamerato L, Khan AM, Schuger CD. 2011. Effect of race on the frequency of postoperative atrial fibrillation following coronary artery bypass grafting. Am J Cardiol, 107 (3):383-386.

Lamb RK, Prabhakar G, Thorpe JA, Smith S, Norton R, Dyde JA. 1988. The use of atenolol in the prevention of supraventricular arrhythmias following coronary artery surgery. Eur Heart J, 9 (1):32-36. 
Lee JK, Klein GJ, Krahn AD, Yee R, Zarnke K, Simpson C, Skanes A, Spindler B. 2000. Ratecontrol versus conversion strategy in postoperative atrial fibrillation: a prospective, randomized pilot study. Am Heart J, 140 (6):871-877.

Lee SH, Lee H, Park JK, Uhm JS, Kim JY, Pak HN, Lee MH, Yoon HG, Joung B. 2017. Gender Difference in the Long-Term Clinical Implications of New-Onset Atrial Fibrillation after Coronary Artery Bypass Grafting. Yonsei Med J, 58 (6):1119-1127.

Lubitz SA, Yin X, Rienstra M, Schnabel RB, Walkey AJ, Magnani JW, Rahman F, McManus DD, Tadros TM, Levy D. 2015. Long-term outcomes of secondary atrial fibrillation in the community: the Framingham Heart Study. Circulation, 131 (19):1648-1655.

Macle L, Cairns J, Leblanc K, Tsang T, Skanes A, Cox JL, Healey JS, Bell A, Pilote L, Andrade JG, Mitchell LB, Atzema C, Gladstone D, Sharma M, Verma S, Connolly S, Dorian P, Parkash R, Talajic M, Nattel S, Verma A. 2016. 2016 Focused Update of the Canadian Cardiovascular Society Guidelines for the Management of Atrial Fibrillation. Can J Cardiol, 32 (10):1170-1185.

Mathew JP, Parks R, Savino JS, Friedman AS, Koch C, Mangano DT, Browner WS. 1996. Atrial fibrillation following coronary artery bypass graft surgery: predictors, outcomes, and resource utilization. MultiCenter Study of Perioperative Ischemia Research Group. Jama, 276 (4):300-306.

Mathew JP, Fontes ML, Tudor IC, Ramsay J, Duke P, Mazer CD, Barash PG, Hsu PH, Mangano DT. 2004. A multicenter risk index for atrial fibrillation after cardiac surgery. Jama, 291 (14):1720-1729.

Melduni RM, Schaff HV, Bailey KR, Cha SS, Ammash NM, Seward JB, Gersh BJ. 2015. Implications of new-onset atrial fibrillation after cardiac surgery on long-term prognosis: a community-based study. Am Heart J, 170 (4):659-668.

Mihos CG, Santana O, Lamas GA, Lamelas J. 2013. Incidence of postoperative atrial fibrillation in patients undergoing minimally invasive versus median sternotomy valve surgery. The Journal of Thoracic and Cardiovascular Surgery, 146 (6):1436-1441.

Murzi M, Cerillo AG, Bevilacqua S, Gilmanov D, Farneti P, Glauber M. 2012. Traversing the learning curve in minimally invasive heart valve surgery: a cumulative analysis of an individual surgeon's experience with a right minithoracotomy approach for aortic valve replacement. Eur J Cardiothorac Surg, 41 (6):1242-1246.

Nattel S. 2002. New ideas about atrial fibrillation 50 years on. Nature, 415 (6868):219-226. 
Park YM, Cha MS, Park CH, Choi CH, Jeon YB, Kang WC, Choi IS, Park KY. 2017. Newly developed post-operative atrial fibrillation is associated with an increased risk of late recurrence of atrial fibrillation in patients who underwent open heart surgery: Longterm follow up. Cardiol J, 24 (6):633-641.

Pillarisetti J, Patel A, Bommana S, Guda R, Falbe J, Zorn GT, Muehlebach G, Vacek J, Sue Min L, Lakkireddy D. 2014. Atrial fibrillation following open heart surgery: long-term incidence and prognosis. J Interv Card Electrophysiol, 39 (1):69-75.

Pokushalov E, Kozlov B, Romanov A, Strelnikov A, Bayramova S, Sergeevichev D, Bogachev-Prokophiev A, Zheleznev S, Shipulin V, Lomivorotov VV, Karaskov A, Po SS, Steinberg JS. 2015. Long-Term Suppression of Atrial Fibrillation by Botulinum Toxin Injection Into Epicardial Fat Pads in Patients Undergoing Cardiac Surgery: OneYear Follow-Up of a Randomized Pilot Study. Circ Arrhythm Electrophysiol, 8 (6):1334-1341.

Pretorius M, Donahue BS, Yu C, Greelish JP, Roden DM, Brown NJ. 2007. Plasminogen activator inhibitor-1 as a predictor of postoperative atrial fibrillation after cardiopulmonary bypass. Circulation, 116 (11 Suppl):I1-7.

Rader F, Wagoner DRV, Ellinor PT, Gillinov AM, Chung MK, Costantini O, Blackstone EH. 2011. Influence of Race on Atrial Fibrillation After Cardiac Surgery. Circulation: Arrhythmia and Electrophysiology, 4 (5):644-652.

Ruan Y, Robinson NB, Naik A, Silva M, Hameed I, Rahouma M, Oakley C, Di Franco A, Zamvar V, Girardi LN, Gaudino M. 2020. Effect of atrial pacing on post-operative atrial fibrillation following coronary artery bypass grafting: Pairwise and network metaanalyses. Int J Cardiol, 302:103-107.

Saksena S, Prakash A, Hill M, Krol RB, Munsif AN, Mathew PP, Mehra R. 1996. Prevention of recurrent atrial fibrillation with chronic dual-site right atrial pacing. Journal of the American College of Cardiology, 28 (3):687-694.

Schwann TA, Al-Shaar L, Engoren MC, Bonnell MR, Goodwin M, Schwann AN, Habib RH. 2018. Effect of new-onset atrial fibrillation on cause-specific late mortality after coronary artery bypass grafting surgery $\dagger$. European Journal of Cardio-Thoracic Surgery, 54 (2):294-301.

Shen J, Lall S, Zheng V, Buckley P, Damiano RJ, Jr., Schuessler RB. 2011. The persistent problem of new-onset postoperative atrial fibrillation: a single-institution experience over two decades. J Thorac Cardiovasc Surg, 141 (2):559-570. 
Stone GW, Sabik JF, Serruys PW, Simonton CA, Généreux P, Puskas J, Kandzari DE, Morice M-C, Lembo N, Brown WM, Taggart DP, Banning A, Merkely B, Horkay F, Boonstra PW, van Boven AJ, Ungi I, Bogáts G, Mansour S, Noiseux N, Sabaté M, Pomar J, Hickey M, Gershlick A, Buszman P, Bochenek A, Schampaert E, Pagé P, Dressler O, Kosmidou I, Mehran R, Pocock SJ, Kappetein AP. 2016. Everolimus-Eluting Stents or Bypass Surgery for Left Main Coronary Artery Disease. New England Journal of Medicine, 375 (23):2223-2235.

Sun X, Hill PC, Lowery R, Lindsay J, Boyce SW, Bafi AS, Garcia JM, Haile E, Corso PJ. 2011. Comparison of frequency of atrial fibrillation after coronary artery bypass grafting in African Americans versus European Americans. Am J Cardiol, 108 (5):669672.

Tabata M, Umakanthan R, Cohn LH, Bolman RM, 3rd, Shekar PS, Chen FY, Couper GS, Aranki SF. 2008. Early and late outcomes of 1000 minimally invasive aortic valve operations. Eur J Cardiothorac Surg, 33 (4):537-541.

Tanawuttiwat T, O'Neill BP, Cohen MG, Chinthakanan O, Heldman AW, Martinez CA, Alfonso CE, Mitrani RD, Macon CJ, Carrillo RG, Williams DB, O'Neill WW, Myerburg RJ. 2014. New-Onset Atrial Fibrillation After Aortic Valve Replacement: Comparison of Transfemoral, Transapical, Transaortic, and Surgical Approaches. Journal of the American College of Cardiology, 63 (15):1510-1519.

Thorén E, Wernroth ML, Christersson C, Grinnemo KH, Jidéus L, Ståhle E. 2020. Compared with matched controls, patients with postoperative atrial fibrillation (POAF) have increased long-term $\mathrm{AF}$ after $\mathrm{CABG}$, and POAF is further associated with increased ischemic stroke, heart failure and mortality even after adjustment for AF. Clin Res Cardiol.

Tulla H, Hippeläinen M, Turpeinen A, Pitkänen O, Hartikainen J. 2015. New-onset atrial fibrillation at discharge in patients after coronary artery bypass surgery: short- and longterm morbidity and mortality. European Journal of Cardio-Thoracic Surgery, 48 (5):747-752.

Turagam MK, Mirza M, Werner PH, Sra J, Kress DC, Tajik AJ, Jahangir A. 2016. Circulating Biomarkers Predictive of Postoperative Atrial Fibrillation. Cardiol Rev, 24 (2):76-87.

Ucar HI, Tok M, Atalar E, Dogan OF, Oc M, Farsak B, Guvener M, Yilmaz M, Dogan R, Demircin M, Pasaoglu I. 2007. Predictive significance of plasma levels of interleukin6 and high-sensitivity C-reactive protein in atrial fibrillation after coronary artery bypass surgery. Heart Surg Forum, 10 (2):E131-135. 
Villareal RP, Hariharan R, Liu BC, Kar B, Lee VV, Elayda M, Lopez JA, Rasekh A, Wils on JM, Massumi A. 2004. Postoperative atrial fibrillation and mortality after coronary artery bypass surgery. J Am Coll Cardiol, 43 (5):742-748.

Vintila A, Stanciu A, Horumba M, Vintila V, Lupusoru M, Gurghean A. 2019. IMPACT OF ATRIAL FIBRILLATION ON QUALITY OF LIFE. Journal of Hypertension, 37.

White HD, Antman EM, Glynn MA, Collins JJ, Cohn LH, Shemin RJ, Friedman PL. 1984. Efficacy and safety of timolol for prevention of supraventricular tachyarrhythmias after coronary artery bypass surgery. Circulation, 70 (3):479-484.

Zacharias A, Schwann TA, Riordan CJ, Durham SJ, Shah AS, Habib RH. 2005. Obesity and risk of new-onset atrial fibrillation after cardiac surgery. Circulation, 112 (21):32473255 .

Zaman AG, Archbold RA, Helft G, Paul EA, Curzen NP, Mills PG. 2000. Atrial fibrillation after coronary artery bypass surgery: a model for preoperative risk stratification. Circulation, 101 (12):1403-1408. 


\section{Appendix}

\subsection{Sworn Statement}

(ehrenwörtliche Erklärung)

I hereby declare that I am familiar with the doctoral regulations of the Medical Faculty of the Friedrich Schiller University.

I wrote the dissertation myself and all aids, personal communications and sources I used are given in my work.

The following people supported me in the selection and evaluation of the material as well as in the preparation of the manuscript: Univ. Prof. Dr. med. Torsten Doenst and Dr. med. Hristo Kirov as well as the other co-authors of the manuscript.

The help of a doctoral advisor was not used and that third parties did not receive any direct or indirect monetary benefits from me for work related to the content of the submitted dissertation.

I have not yet submitted the dissertation as an examination paper for a state or other scientific examination.

I have not submitted the same, essentially similar or a different dissertation to another university as a dissertation. 


\subsection{Acknowledgments}

I would like to thank Univ. Prof. Dr. med. Torsten Doenst for guidance, trust and patience. His competent support had fundamental importance for this work, and his commitment with research and with teaching moulds admirable values that make him a great example for me not only in the clinical activities, but especially in the scientific field.

I would like also to thank all the co-authors of the publication, in special Dr. med Hristo Kirov. They supported me with technical advice and instructions, which were fundamental to perform this work.

Finally, I am totally grateful for the constant support from my parents, my brother and my friends. 